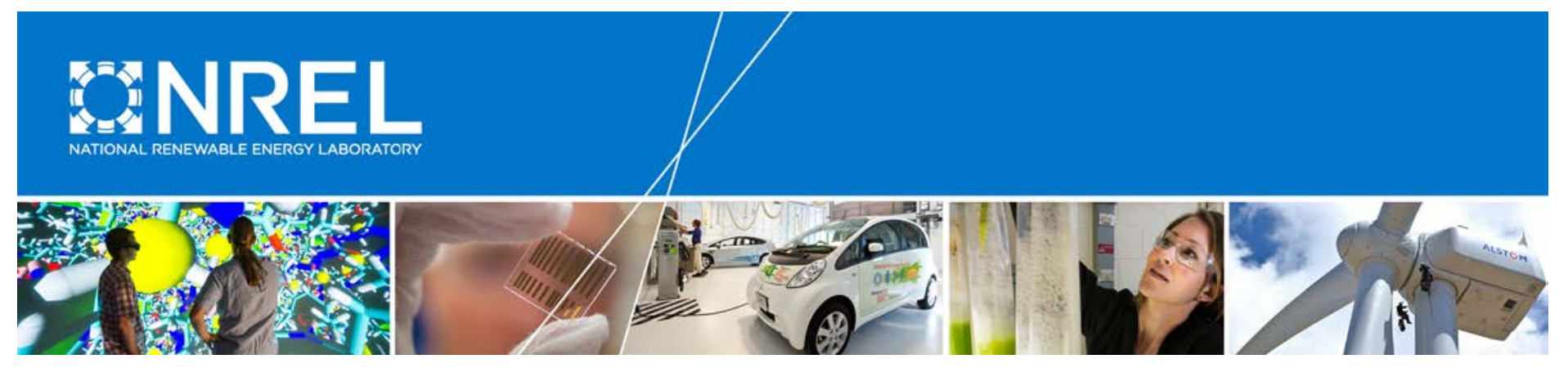

\title{
Modeling the Integrated Expansion of the Canadian and U.S. Power Sectors with the Regional Energy Deployment System (ReEDS)
}

Owen Zinaman, Eduardo Ibanez, Donna Heimiller, Kelly Eurek, and Trieu Mai National Renewable Energy Laboratory

NREL is a national laboratory of the U.S. Department of Energy Office of Energy Efficiency \& Renewable Energy Operated by the Alliance for Sustainable Energy, LLC

This report is available at no cost from the National Renewable Energy Laboratory (NREL) at www.nrel.gov/publications.

Technical Report

NREL/TP-6A20-63797

July 2015 


\section{Modeling the Integrated Expansion of the Canadian and U.S. Power Sectors with the Regional Energy Deployment System (ReEDS)}

Owen Zinaman, Eduardo Ibanez, Donna Heimiller, Kelly Eurek, and Trieu Mai National Renewable Energy Laboratory

Prepared under Task No. DP12.4010

NREL is a national laboratory of the U.S. Department of Energy Office of Energy Efficiency \& Renewable Energy Operated by the Alliance for Sustainable Energy, LLC

This report is available at no cost from the National Renewable Energy Laboratory (NREL) at www.nrel.gov/publications.

National Renewable Energy Laboratory 15013 Denver West Parkway Golden, CO 80401

303-275-3000 • www.nrel.gov

\section{Technical Report}

NREL/TP-6A20-63797

July 2015

Contract No. DE-AC36-08G028308 


\title{
NOTICE
}

This report was prepared as an account of work sponsored by an agency of the United States government. Neither the United States government nor any agency thereof, nor any of their employees, makes any warranty, express or implied, or assumes any legal liability or responsibility for the accuracy, completeness, or usefulness of any information, apparatus, product, or process disclosed, or represents that its use would not infringe privately owned rights. Reference herein to any specific commercial product, process, or service by trade name, trademark, manufacturer, or otherwise does not necessarily constitute or imply its endorsement, recommendation, or favoring by the United States government or any agency thereof. The views and opinions of authors expressed herein do not necessarily state or reflect those of the United States government or any agency thereof.

This report is available at no cost from the National Renewable Energy Laboratory (NREL) at www.nrel.gov/publications.

Available electronically at SciTech Connect http:/www.osti.gov/scitech

Available for a processing fee to U.S. Department of Energy and its contractors, in paper, from:

\author{
U.S. Department of Energy \\ Office of Scientific and Technical Information \\ P.O. Box 62 \\ Oak Ridge, TN 37831-0062 \\ OSTI http://www.osti.gov \\ Phone: 865.576.8401 \\ Fax: 865.576.5728 \\ Email: reports@osti.gov
}

Available for sale to the public, in paper, from:

\author{
U.S. Department of Commerce \\ National Technical Information Service \\ 5301 Shawnee Road \\ Alexandria, VA 22312 \\ NTIS http://www.ntis.gov \\ Phone: 800.553 .6847 or 703.605 .6000 \\ Fax: 703.605.6900 \\ Email: orders@ntis.gov
}




\section{Preface}

The purpose of this report is to document a development effort that created a robust representation of the combined capacity expansion of the U.S. and Canadian electric sectors in the U.S. Department of Energy's National Renewable Energy Laboratory (NREL) Regional Energy Deployment System (ReEDS) model. The first portion of this report is focused on documenting augmentations made to the ReEDS model, building on prior work by Martinez et al. (2013). The work conducted and documented here aims to provide insights into the types of analysis this novel modeling capability can enable, rather than analyzing potential U.S - Canada power sector futures. The model is limited to long-term capacity expansion and high-levels steady-state operations and does not include detailed production cost of dynamic simulations. Development and validation work was conducted throughout the 2014 calendar year, relying heavily on the National Energy Board's Canadian Energy Futures 2013 (NEB 2013) study for input data, as well as significant communication with Natural Resources Canada staff.

The analysis was conducted in the fall of 2014 and relies on model versions and data available at that time. In particular, the analysis uses published data inputs where available and applicable. In some cases, internal data and assumptions are applied to account for rapid changes in the market outlook that are not captured by the published literature. The version of ReEDS used is the NREL Base Model as of October 2014.

This body of work includes a sensitivity analysis that considers several future power sector scenarios out to 2036. The analysis uses a self-consistent framework to evaluate the impact of assumptions on the model behavior. In particular, we model the impact of natural gas price projections, increased Canadian hydropower deployment, and increased renewable energy (RE) generation penetrations. While none of the scenarios presented are intended to be a forecast or prediction, the scenarios can collectively be used to understand trends and drivers within the modeled framework. 


\section{Abstract}

The purpose of this report is to document a development effort that created a robust representation of the combined capacity expansion of the U.S. and Canadian electric sectors within the NREL ReEDS model. We demonstrate this newly established capability through an illustrative sensitivity analysis. In conducting the sensitivity analysis, we describe the value of an integrated modeling approach. Overall, the work conducted and documented here aims to provide insights into the types of analysis this novel modeling capability can provide, rather than analyzing potential U.S. - Canada power sector futures.

The development effort, building on previously published work, comprehensively updated a number of model assumptions, such as fuel price and load projections, existing fleet specifications (including expected retirements and new builds), renewable energy (RE) cost and performance projections and resource characterizations, and existing regulation and policy suites.

The abbreviated scenario analysis effort was designed to understand drivers behind various Canadian-U.S. power sector futures out to $2036 .{ }^{1} \mathrm{We}$ model the impact of natural gas prices, increased Canadian hydropower deployment, and increased RE penetrations. None of the scenarios presented are intended to be a forecast or prediction. The sample results analyzed in this report show the highly dynamic nature of the modeling tool as it performs a simultaneous optimization of the two countries' generation portfolios. The interactions between the two countries go beyond energy generation and also include firm capacity contracts and RE credits.

The reference scenario results show a significant increase in wind generation in both the United States and Canada with a gradual retirement of coal and nuclear energy. The evolution of net energy and firm capacity exchange is very dynamic through the span of the analysis period and drives significant investment in transmission capacity across the border, almost doubling the existing capacity of transmission lines. The exchange of energy is driven by regional stories. ISO-NE and NYISO import energy throughout the analysis period. However, in the Western Interconnection we observe increasing imports to Canada from the United States, whereas the exchanges with MISO switch directions.

The five sensitivity scenarios analyzed exhibit distinct infrastructure portfolio evolutions relative to the reference scenario for both the U.S. and Canada. Exchanges of energy and capacity between the two countries differ as well. Parameters such as fuel prices, hydropower deployment, and prescribed RE penetration have a significant impact on the least-cost decisionmaking in ReEDS. A more exhaustive search of the parameter space would provide important insights into identifying deployment trends and drivers resulting from the integrated planning of the U.S. and Canadian power systems.

\footnotetext{
${ }^{1}$ Scenario analysis was conducted through the 2036 ReEDS solve year to mimic the time horizon in the National Energy Board “Canada's Energy Future 2013 - Energy Supply and Demand Projections to 2035” study.
} 


\section{Table of Contents}

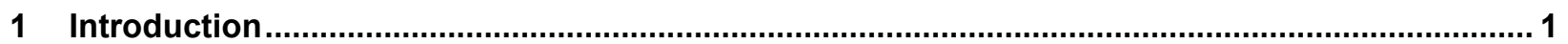

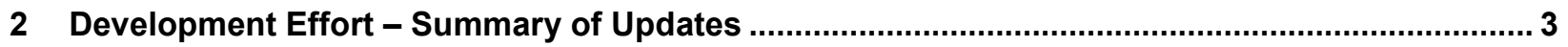

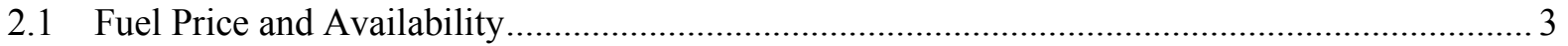

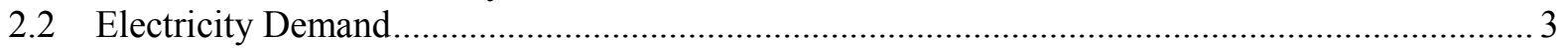

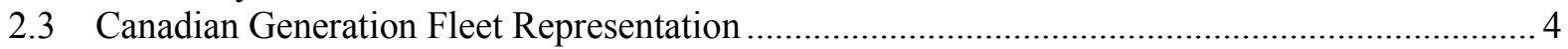

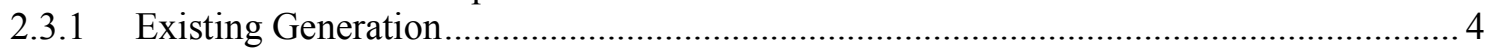

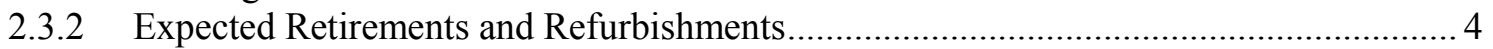

2.3.3 Expected New Infrastructure Construction ............................................................ 4

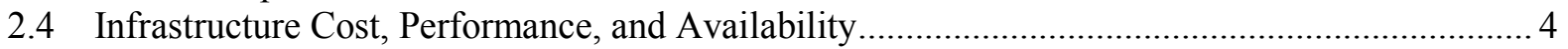

2.4.1 Conventional Generation Technology Representation.................................................. 5

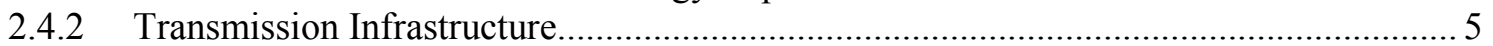

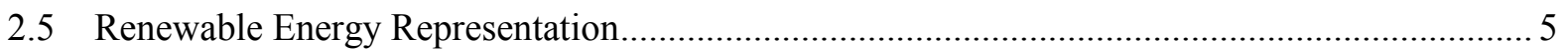

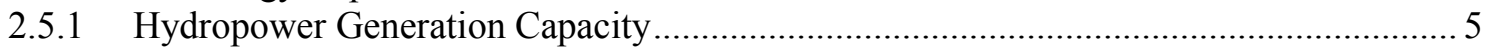

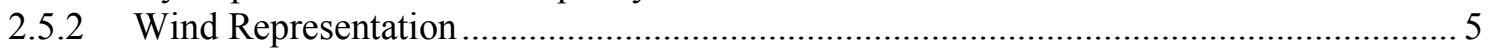

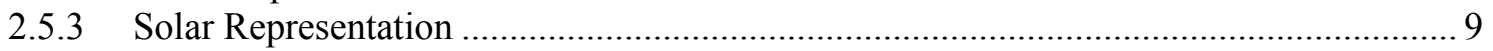

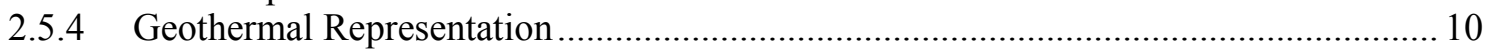

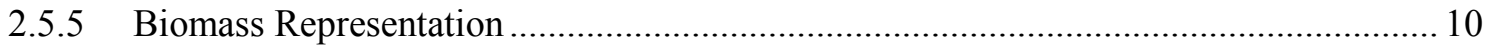

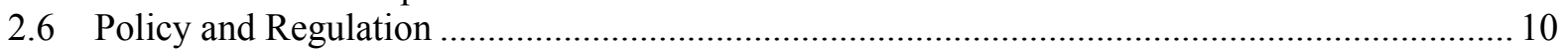

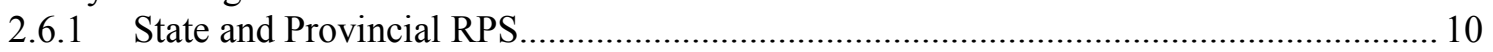

2.6.2 Other State, Provincial, and Regional Electricity Policy ............................................. 10

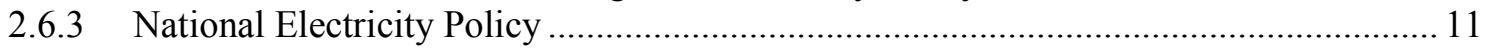

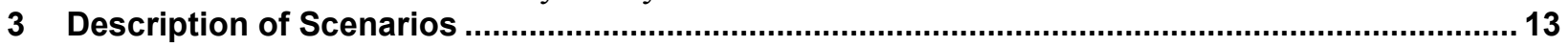

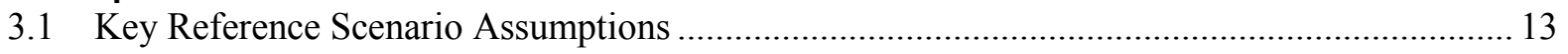

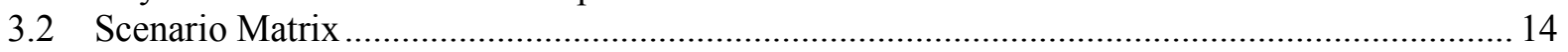

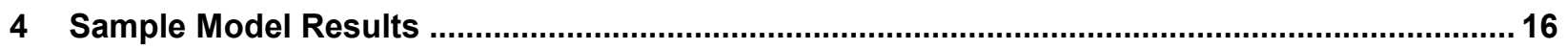

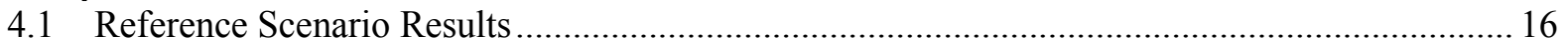

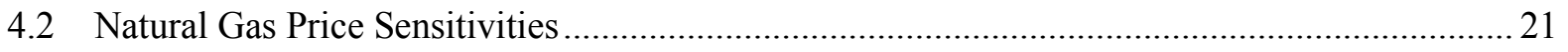

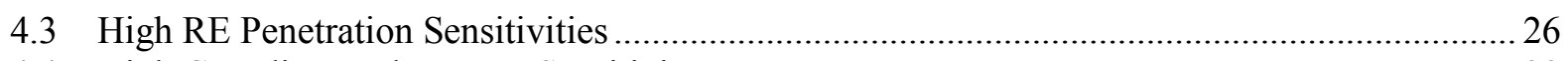

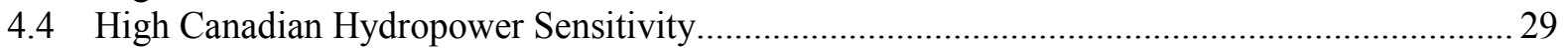

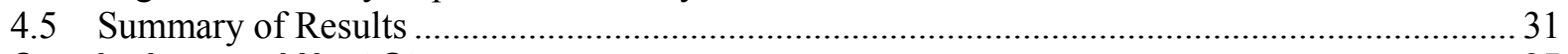

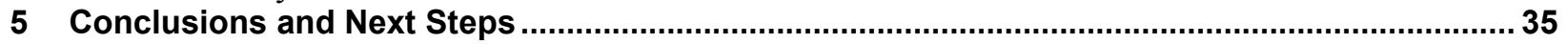




\section{List of Figures}

Figure 1. Map of United States and Canadian BAs and resource regions ............................................... 2

Figure 2. Map of EIA Census Region boundaries extended to Canadian provinces ................................... 3

Figure 3. Capacity factor versus average wind speed in the western United States ................................. 6

Figure 4. Capacity factor versus average wind speed in the U.S. Great Lakes.......................................... 7

Figure 5. Capacity factor versus average wind speed in the northeast United States ................................ 7

Figure 6. Land exclusions applied to Canadian wind resource........................................................ 8

Figure 7. Wind resource location and classification in the United States and Canada ............................ 8

Figure 8. Average annual utility-scale PV capacity factors for ReEDS BAs ....................................... 9

Figure 9. Natural gas price forecasts from AEO 2014 for the gas sensitivities ....................................... 15

Figure 10. Capacity by generator type for the United States and Canada, "BaseCase" scenario ............... 16

Figure 11. Generation by type for the United States and Canada, "BaseCase" scenario........................... 17

Figure 12. Breakdown of generation by country for the beginning and the end of the simulation,

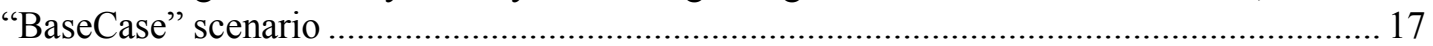

Figure 13. Wind capacity growth by Canadian provinces, "BaseCase" scenario ..................................... 18

Figure 14. Net energy interchange between Canada and the United States, "BaseCase" scenario ............ 18

Figure 15. Net energy interchange between countries (line) along with net interchange by zone (bars),

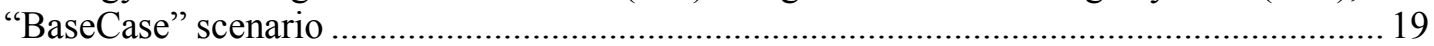

Figure 16. Transmission capacity across the U.S. - Canada border, "BaseCase" scenario....................... 19

Figure 17. New transmission investments between ReEDS BAs, "BaseCase" scenario by 2036............ 20

Figure 18. Net firm capacity exchange between countries, "BaseCase" scenario ..................................... 20

Figure 19. National average electricity (left) and natural gas (right) prices for Canada and the United

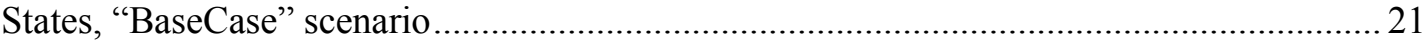

Figure 20. $\mathrm{CO}_{2}$ emissions (left) and average $\mathrm{CO}_{2}$ intensity by country, "BaseCase" scenario ................. 21

Figure 21. United States and Canadian average natural gas prices for the natural gas sensitivities ........... 22

Figure 22. Change in capacity for natural gas sensitivities, compared to "BaseCase" scenario................. 22

Figure 23. Change in generation for natural gas sensitivities, compared to "BaseCase" scenario .............23

Figure 24. Net energy interchange between countries for the natural gas sensitivities ........................... 23

Figure 25. Net energy interchange between countries (line) along with net interchange by zone (bars) for

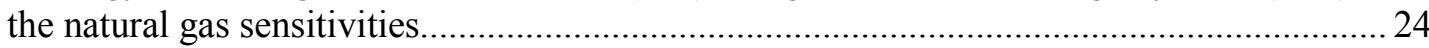

Figure 26. Comparison of gas CC and wind generation for the natural gas sensitivities in selected states and provinces

Figure 27. New international transmission capacity for natural gas sensitivities ..................................... 25

Figure 28. Fraction of generation from RE in "BaseCase" scenario, compared to RE requirement .......... 26

Figure 29. Change in capacity for high RE sensitivities, compared to "BaseCase" scenario.................... 27

Figure 30. Change in generation for high RE sensitivities, compared to "BaseCase" scenario ................ 28

Figure 31. Fraction of generation from RE for the high RE sensitivities ............................................ 28

Figure 32. Net energy interchange between countries for the high RE sensitivities................................ 29

Figure 33. Change in capacity for "HiCanHydro" sensitivity, compared to "BaseCase" scenario ............ 30

Figure 34. Change in generation for "HiCanHydro" sensitivity, compared to "BaseCase" scenario......... 30

Figure 35. Net energy interchange between countries for the "HiCanHydro" sensitivity ........................ 31

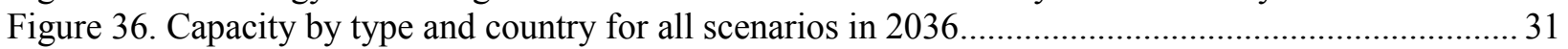

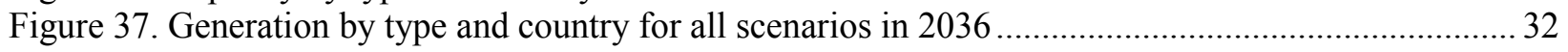

Figure 38. New international transmission capacity for all scenarios ............................................. 32

Figure 39. New international transmission capacity by zone for all scenarios ........................................ 33

Figure 40. Net energy interchange between countries for all scenarios.............................................. 33

Figure 41. Electricity prices for Canada and the United States (left) and combined U.S./Canada natural

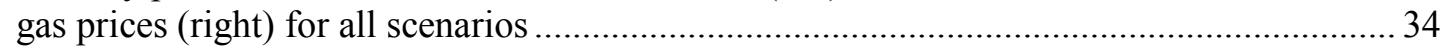

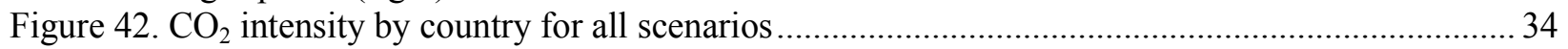




\section{List of Tables}

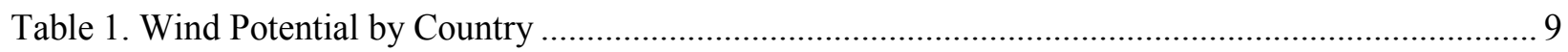

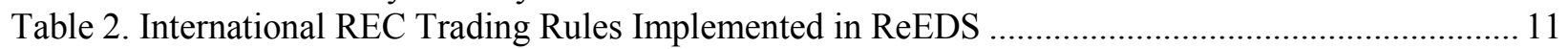

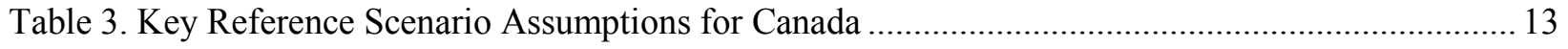

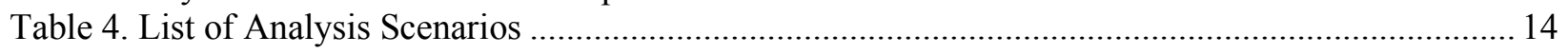




\section{Introduction}

The United States and Canada share an important electricity relationship, physically interconnected at over 35 points at the high-voltage level from New England to the Pacific Northwest (CEA, 2010). ${ }^{2}$ This integration of electricity resources allows for greater coordination, higher levels of reliability, and significant opportunity for expanding access to affordable, low-carbon energy.

In this report, we document a development effort to update an endogenous treatment of the integrated U.S. - Canada electricity sectors in the NREL Regional Energy Deployment System (ReEDS) model. This effort builds on previous work conducted by Martinez et al. (2013), which initially expanded the ReEDS modeling framework to allow for the addition of Canadian balancing areas. We also present results from an abbreviated scenario analysis, using this endogenous treatment, which demonstrates the new capability and yields initial insights into the influence of various drivers on power sector deployment. None of the scenarios presented are intended to be a forecast or prediction. The sample results analyzed in this report are intended to demonstrate the newly established capability and illustrate the highly dynamic nature of the modeling tool as it performs a simultaneous optimization of the two countries' generation portfolios.

The ReEDS model ${ }^{3}$ is a capacity expansion and dispatch model of the United States. The ReEDS algorithm is designed to economically optimize, in two-year solve increments: the type and location of conventional and renewable resource development; the transmission infrastructure expansion requirements of those installations; and the composition and location of generation, storage, and demand-side technologies needed to satisfy regional demand requirements and maintain grid system adequacy. ${ }^{4}$ The model also considers technology, resource, and policy constraints, including state renewable portfolio standards (RPS). The ReEDS model has been utilized in a wide array of analyses, including the U.S. Department of Energy (DOE) 20\% Wind Energy by 2030 study (DOE 2008), DOE SunShot Vision Study (DOE 2012), the Renewable Electricity Futures Study (NREL 2012), DOE Wind Vision Study (DOE 2015) and others (Logan et al. 2013, and Mai et al. 2013). For detailed documentation of an earlier version of the model, see Short et al. (2011).

The model presented in this report represents the contiguous 48 states in the United States and 9 Canadian provinces. ${ }^{5}$ The simulated regions are represented with high spatial resolution, comprising 154 model balancing areas (BAs) and 403 regions with distinct wind ${ }^{6}$ power

\footnotetext{
${ }^{2}$ There are many more points of interconnection at the distribution level.

${ }^{3}$ ReEDS is an electric sector capacity expansion model developed at the NREL. For more information on the model including a publication list of research using the model, see http://www.nrel.gov/analysis/reeds/.

${ }^{4}$ ReEDS is designed to comply with exogenously defined reserve margin requirements, but does not simulate other reliability issues related such as voltage or transient stability. However, ReEDS includes a diverse set of grid interconnection costs for new generation resources, intended to account for necessary grid improvements (e.g., substation upgrades, line extensions, etc.) as a result of new capacity additions.

${ }^{5}$ Labrador is explicitly modeled, but Newfoundland Island is not. The Canadian Territories (Yukon, Northwest, Nunavut) are not modeled. Prince Edward Island (p155) and Newfoundland Island (p156) are contained within the modeling framework but are not explicitly modeled - this could be the subject of future work.

${ }^{6}$ These 403 regions also have distinct concentrating solar power (CSP) resource characteristics for the contiguous United States; however, Direct Normal Irradiance insolation is considered too low for CSP resources in Canada.
} 
resource characteristics. This high spatial resolution is designed to represent the relative value of geographically constrained renewable power resources. Figure 1 shows the regional structure of the model. ${ }^{7}$

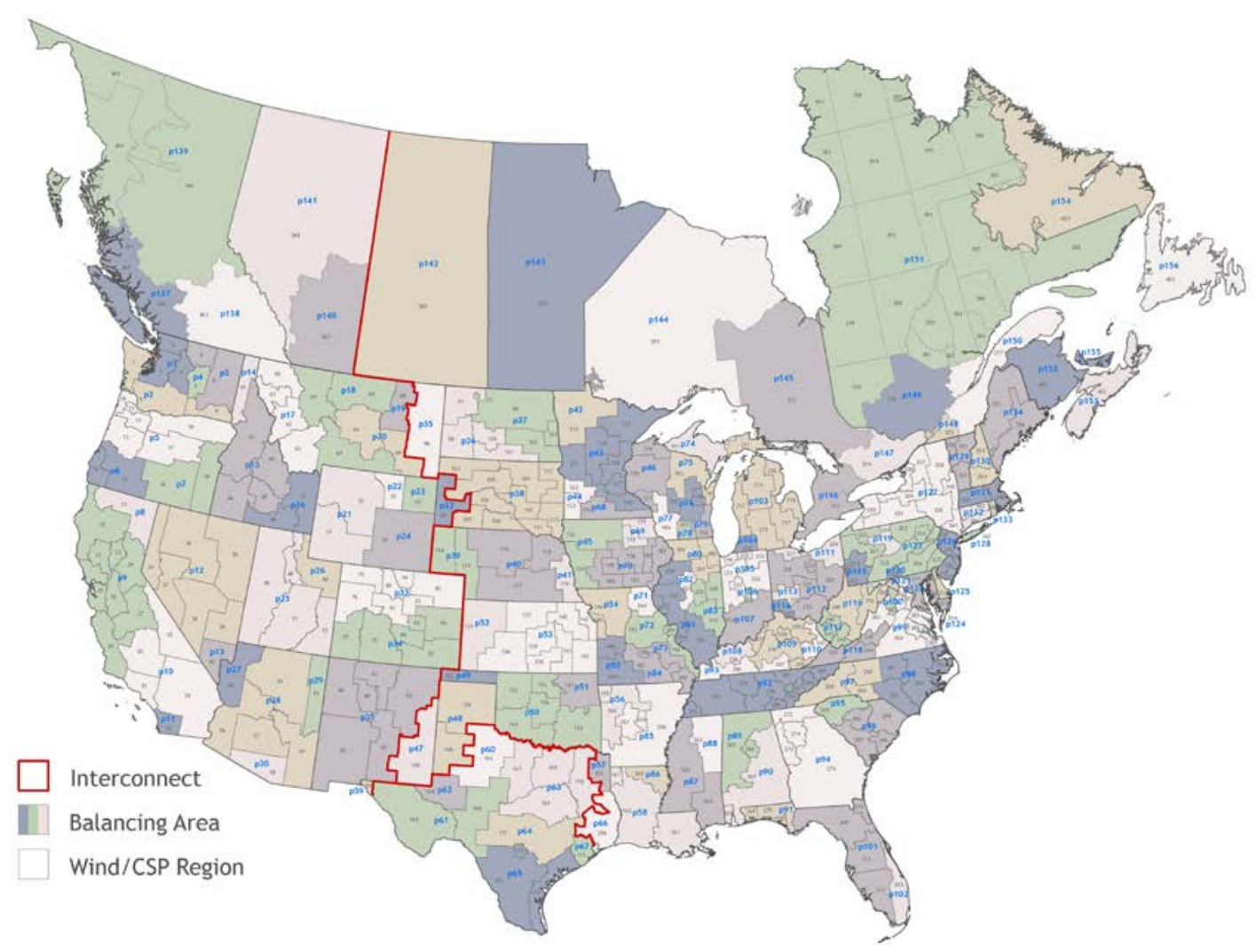

Figure 1. Map of United States and Canadian BAs and resource regions

None of the scenarios presented are intended to be forecasts or predictions; rather, ReEDS provides a self-consistent framework to assess the potential impact of different technology, market, and policy conditions on technology deployment. This body of work relies on a sensitivity analysis that considers several power sector futures out to 2036. Scenario analysis was conducted through the 2036 ReEDS solve year to mimic the time horizon in NEB (2013).

Section 2 of this report describes the development effort - namely, the data and modeling representation updates performed relative to Martinez et al. (2013). Section 3 describes the analysis, including the scenario matrix and the key input assumptions of the reference scenario. Section 4 presents in-depth results from the reference scenario and the sensitivity analysis. Section 5 concludes and proposes next steps in development and analysis.

\footnotetext{
${ }^{7}$ Prince Edward Island (BA p155) and Newfound Island (BA p156) are not modeled.
} 


\section{Development Effort - Summary of Updates}

Martinez et al. (2013) describes the core model structure developments and data processing steps used in the initial integrated U.S.-Canada representation in ReEDS. The present development effort builds on this prior work and, thus, this section will be focused solely on the updates to Martinez et al. (2013).

\subsection{Fuel Price and Availability}

Natural gas supply and demand dynamics are represented in ReEDS through regional supply curves along Energy Information Administration (EIA) Census Region boundaries. These supply curves are derived from Annual Energy Outlook (AEO) 2014 (EIA 2014); price elasticity of demand (i.e., change in price with respect to usage) is derived from an internal NREL regression analysis of scenarios in EIA (2014). For Canadian provinces, we modify the U.S.-only regional supply curves based on consumption projections from National Energy Board's Canada's Energy Future 2013 (NEB 2013). Natural gas supply curves are modified to capture the additional supply and demand for natural gas in Canadian regions; geographically adjacent Canadian provinces are assigned to EIA Census Regions. A map of this allocation is shown in Figure 2.

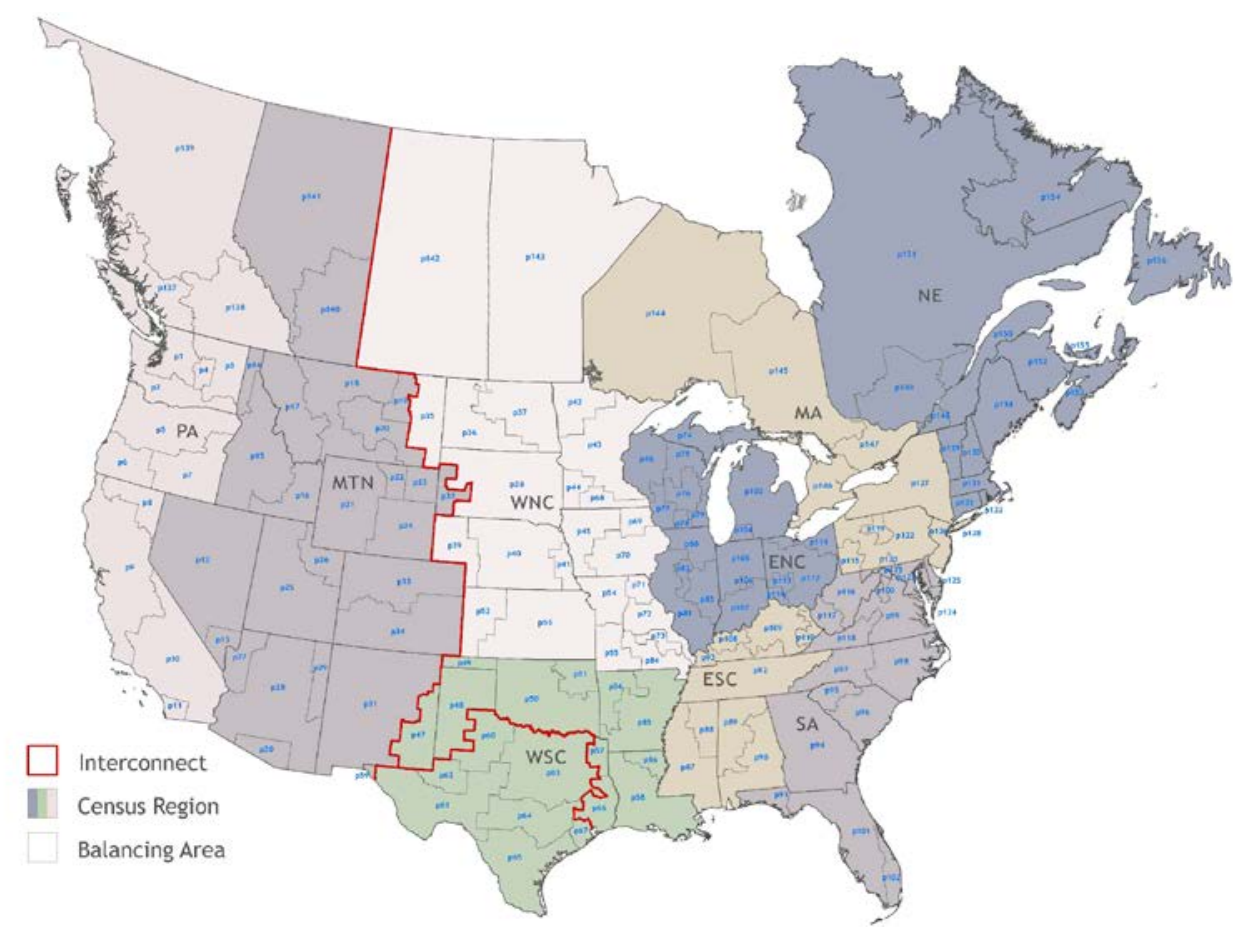

Figure 2. Map of EIA Census Region boundaries extended to Canadian provinces

Canadian coal prices are provincial and represented as inelastic to changes in consumption; they are consistent with Canadian provincial coal price projections from NEB (2013). The price of nuclear fuel for Canadian units is assumed to be consistent with the AEO 2014 Reference Case data for the United States (EIA 2014).

\subsection{Electricity Demand}

Annual electricity demand projections were updated to the NEB (2013) reference scenario, and reflects annual provincial load reduced by customer-sited electricity cogeneration. Provincial and 
zonal load shapes are preserved from Martinez et al. (2013). For provinces comprised of multiple ReEDS BAs (Alberta, British Columbia, Ontario, Quebec), the spatial distribution of annual provincial electricity demand among BAs is preserved from Martinez et al. (2013).

\subsection{Canadian Generation Fleet Representation}

This section describes the data sets used to define the existing fleet of Canadian generation units, as well as expected retirements, refurbishment schedules and new construction of generation infrastructure. Consistent with the contiguous United States fleet representation in ReEDS, Ventyx Velocity Suite is used as a basis for Canadian generation units (Ventyx Energy 2014). This data set is then cross-referenced with NEB (2013) and provincial energy plans to represent the Canadian fleet.

\subsubsection{Existing Generation}

The Ventyx Velocity Suite is used to define the core characteristics of the existing Canadian unit fleet, including plant technology, capacity, and heat rate. We use Ontario's Long Term Energy Plan (OME 2013) to represent the capacity of existing fleet of nuclear units in Ontario, along with Ventyx Energy (2014), to characterize the nuclear units in New Brunswick and Quebec.

\subsubsection{Expected Retirements and Refurbishments}

A schedule of expected retirements and refurbishments is derived from the Ventyx Velocity Suite data set as of November 2014. We use Ontario's Long Term Energy Plan (OME 2013) to represent the schedule of expected nuclear unit refurbishments and retirements in Ontario. The refurbished Point Lepreau Nuclear Generating Station in New Brunswick is assumed to become operational in the 2014 solve year $^{8}$ and retired in 2044. Gentilly Nuclear Generating Station in Quebec is assumed to retire at the end of 2012 (NEB 2013).

\subsubsection{Expected New Infrastructure Construction}

Consistent with the ReEDS representation of the contiguous United States, projects under construction or that meet other project maturity criteria (e.g., executed power purchase agreements) are prescribed for Canadian provinces. This list of prescribed units is derived from cross-referencing Ventyx Energy (2014) with the list of prescribed builds of specific units from NEB (2013). NEB (2013) also prescribes "general" units which analysts expect to be built, but those units do not yet have a name; consistent with our methodology for modeling prescribed builds in ReEDS for the lower 48 United States, we choose to not prescribe these units as there is generally a greater degree of uncertainty as to the ultimate commissioning of these projects.

\subsection{Infrastructure Cost, Performance, and Availability}

Generally, ReEDS does not endogenously model cost reductions or performance improvements in technologies from "learning-by-doing" or manufacturing economies of scale. Rather, technology cost and performance assumptions are defined as exogenous inputs and are thus unaffected by deployment volumes. Furthermore, the model assumes no limitations with respect to domestic or global manufacturing capacity to meet demand for new generation equipment; for a given year, the manufacturing sector is assumed to be able to meet the demand. We also assume that sufficient debt and equity financing is available from capital markets to construct all

\footnotetext{
${ }^{8}$ Point Lepreau was restarted in late 2012, but ReEDS solves the expansion problem in two-year increments.
} 
projects that the model determines should be built. ReEDS does not consider all regulatory, permitting, and siting challenges faced by generation and transmission project developers or electric utilities.

\subsubsection{Conventional Generation Technology Representation}

Assumed cost and performance characteristics for conventional power plant technologies are consistent with the EIA's AEO 2014 Reference Case (EIA 2014) and other sources in NREL (2014). These technologies include coal-fired generation, natural gas combined cycle (CC) and combustion turbine facilities, hydropower facilities, nuclear power plants, and biomass technologies. $^{9}$

\subsubsection{Transmission Infrastructure}

Existing transmission infrastructure data is consistent with Martinez et al. (2013). Alternating current (AC) transmission infrastructure is allowed to be built without restriction beginning in solve year 2020; prior to that, a truncated transmission supply curve is made available comprised of expected and likely builds. International AC transmission builds are assumed to have the same capital costs as U.S. construction. Direct current (DC) transmission infrastructure construction is not allowed unless it is exogenously prescribed. The current simulations did not include any new DC transmission line across the Canada-U.S. border.

\subsection{Renewable Energy Representation}

\subsubsection{Hydropower Generation Capacity}

Diverging from Martinez et al. (2013), we do not use a small hydropower unit supply curve. Due to a lack of available hydropower supply curves compatible with those assumed for the United States, we do not allow ReEDS to endogenously select to build new hydropower capacity in Canada. Rather, we rely on a schedule of expected builds from NEB (2013) for new Canadian hydropower units. Only builds from NEB (2013) that reflect specific projects (as opposed to general expectations of new construction) are prescribed. To complement this assumption, and given the importance of hydropower in the Canadian resource mix, we develop a sensitivity scenario with higher levels of hydro deployment. While annual hydropower output can fluctuate significantly from year to year based on precipitation and other weather patterns, we assume that there is no inter-annual variation in available hydropower generation in ReEDS; rather, average capacity factors are assumed that reflect long-run historical averages. Seasonal hydropower capacity factors are specified for each Canadian province, derived from NEB (2013).

\subsubsection{Wind Representation}

Wind cost and performance projections are based on an NREL (2014). Potential wind plant locations are grouped into techno-resource groups (TRGs) for representation in the ReEDS model. TRGs are designed to bin the total resource pool by the average wind speed and assumed turbine technologies by region. There are five TRGs for land-based wind technology and 10 TRGs for offshore wind technology, representing three different depth deployment technologies. A more detailed description of TRGs is presented in DOE's Wind Vision study (DOE 2015). The

\footnotetext{
${ }^{9}$ For technologies for which EIA models an "advanced" option and a "conventional" option with different cost and performance assumptions, we use the average in the ReEDS model.
} 
potential U.S. wind resource is subject to standard exclusions. A complete list of these exclusions is available in Lopez et al. (2012).

The classification of wind resource into TRGs requires processing typical wind speed profiles, which NREL licenses from AWS Truepower for the United States. The Canadian wind dataset available at the time of this development effort had geographical information of average wind speed (Environment Canada 2008). In order to convert average wind speed into TRGs, we performed an analysis of the U.S. wind resource data, which showed a high level of correlation between average wind speed and capacity factor. Ultimately, annual capacity factor determines the TRG classification. Linear regressions were performed for the western (Figure 3), central (Figure 4) and eastern (Figure 5) U.S. states adjacent to Canada to account for distinct regional wind climates; these regression curves were used to translate Canadian average wind speed into annual average capacity factor and thereafter assign each potential wind resource a TRG.

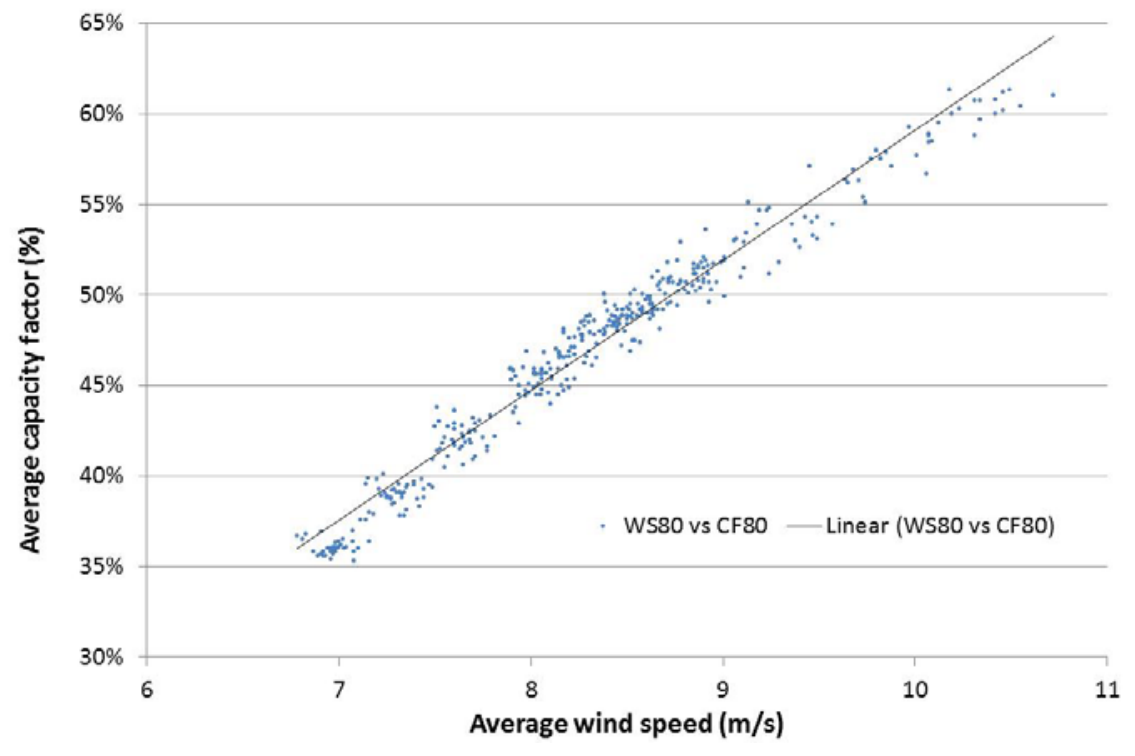

Figure 3. Capacity factor versus average wind speed in the western United States 


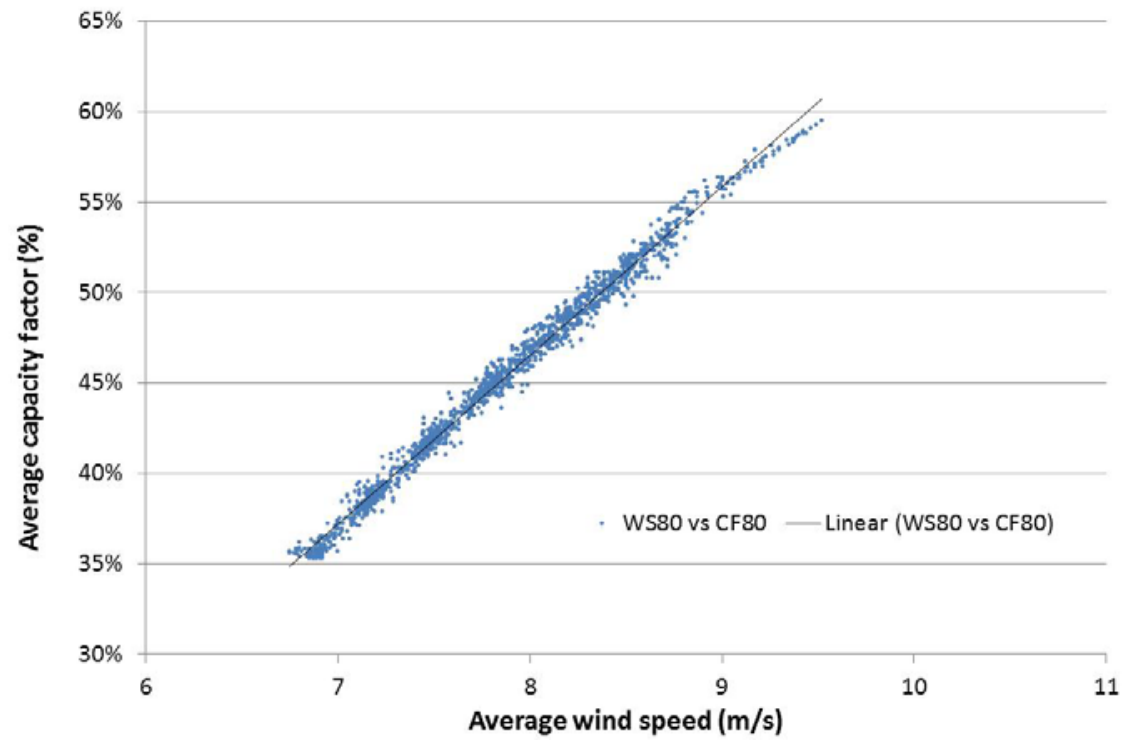

Figure 4. Capacity factor versus average wind speed in the U.S. Great Lakes

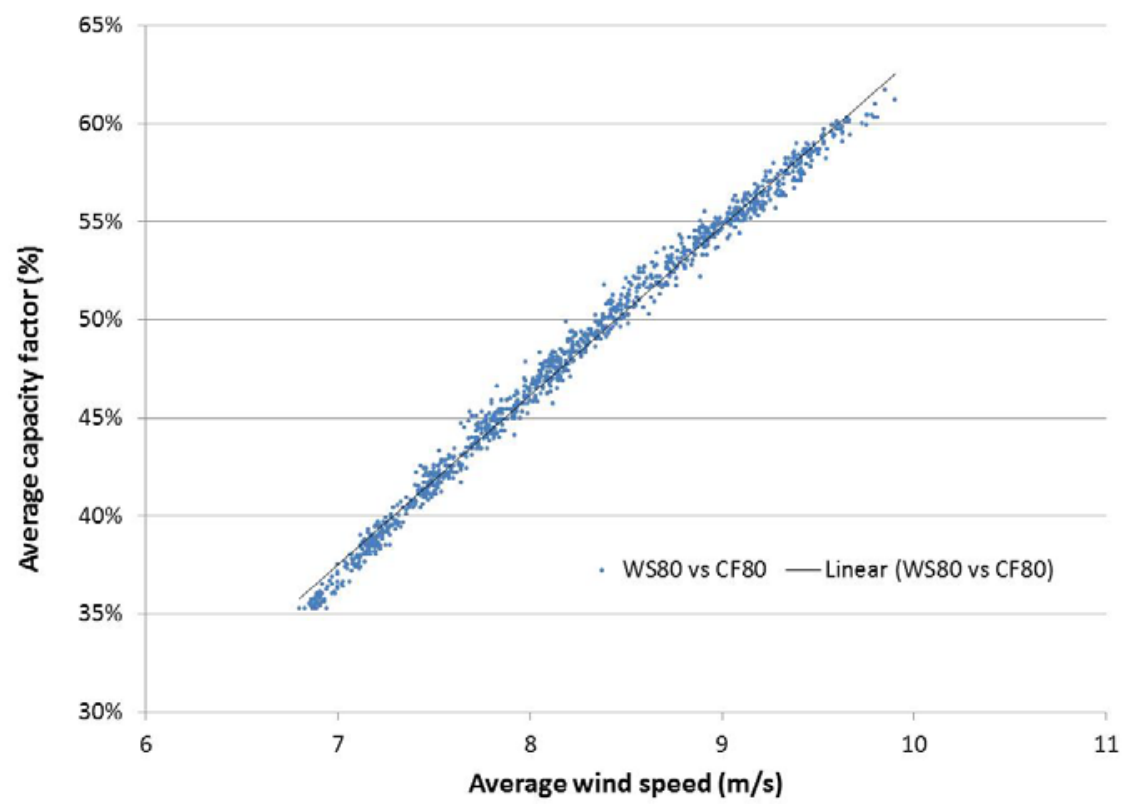

Figure 5. Capacity factor versus average wind speed in the northeast United States

Land exclusions are applied to the Canadian wind resource data, implementing the same categories used in the U.S. analysis wherever adequate Canadian data was available. These include national parks and competing land use categories. Figure 6 illustrates the areas that were excluded from the analysis for potential wind development.

Figure 7 represents the geographic distribution of wind resource across the United States and Canada. Potential resources across TRGs by country, as modeled, are included in Table 1. 


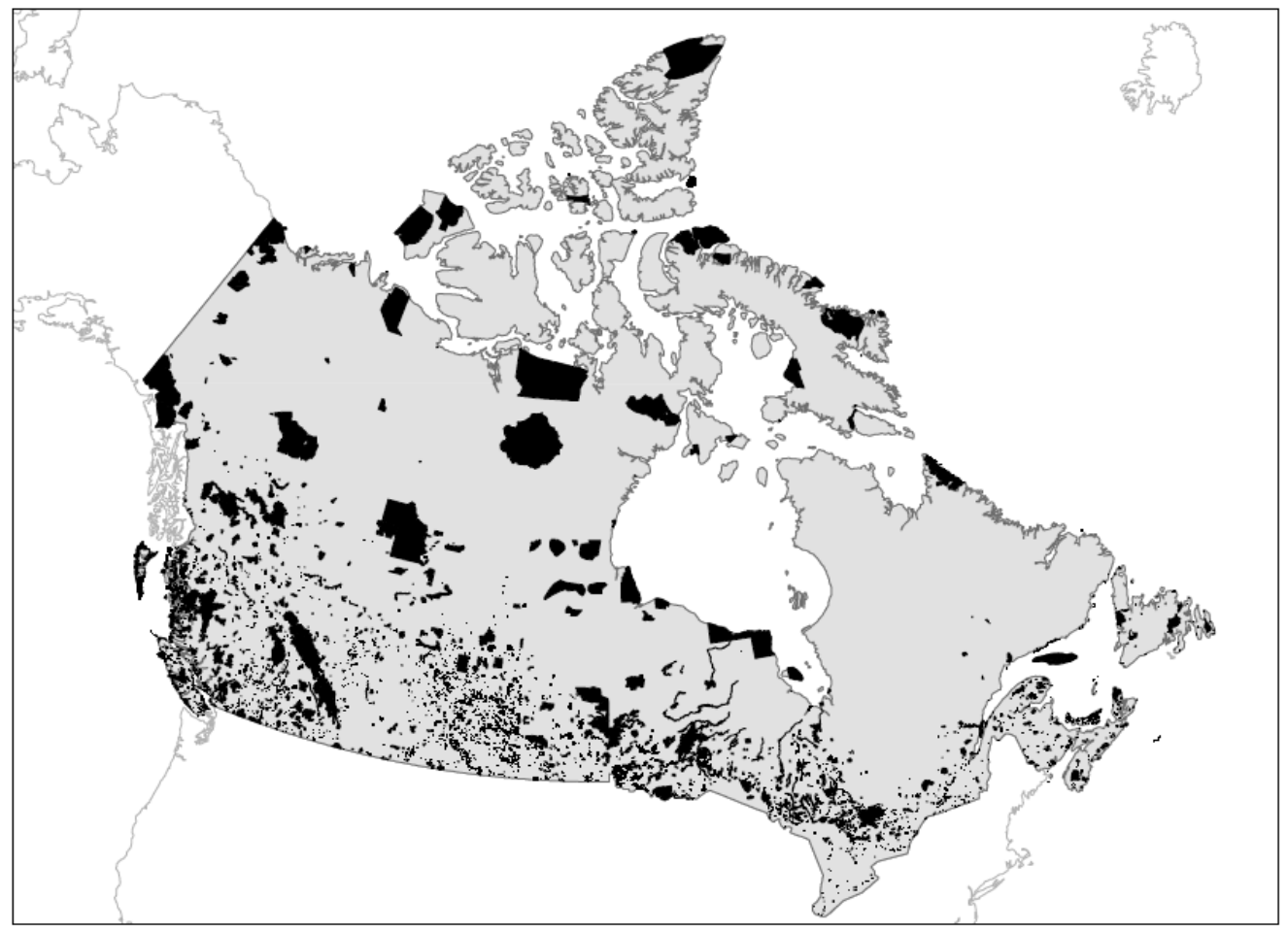

Figure 6. Land exclusions applied to Canadian wind resource

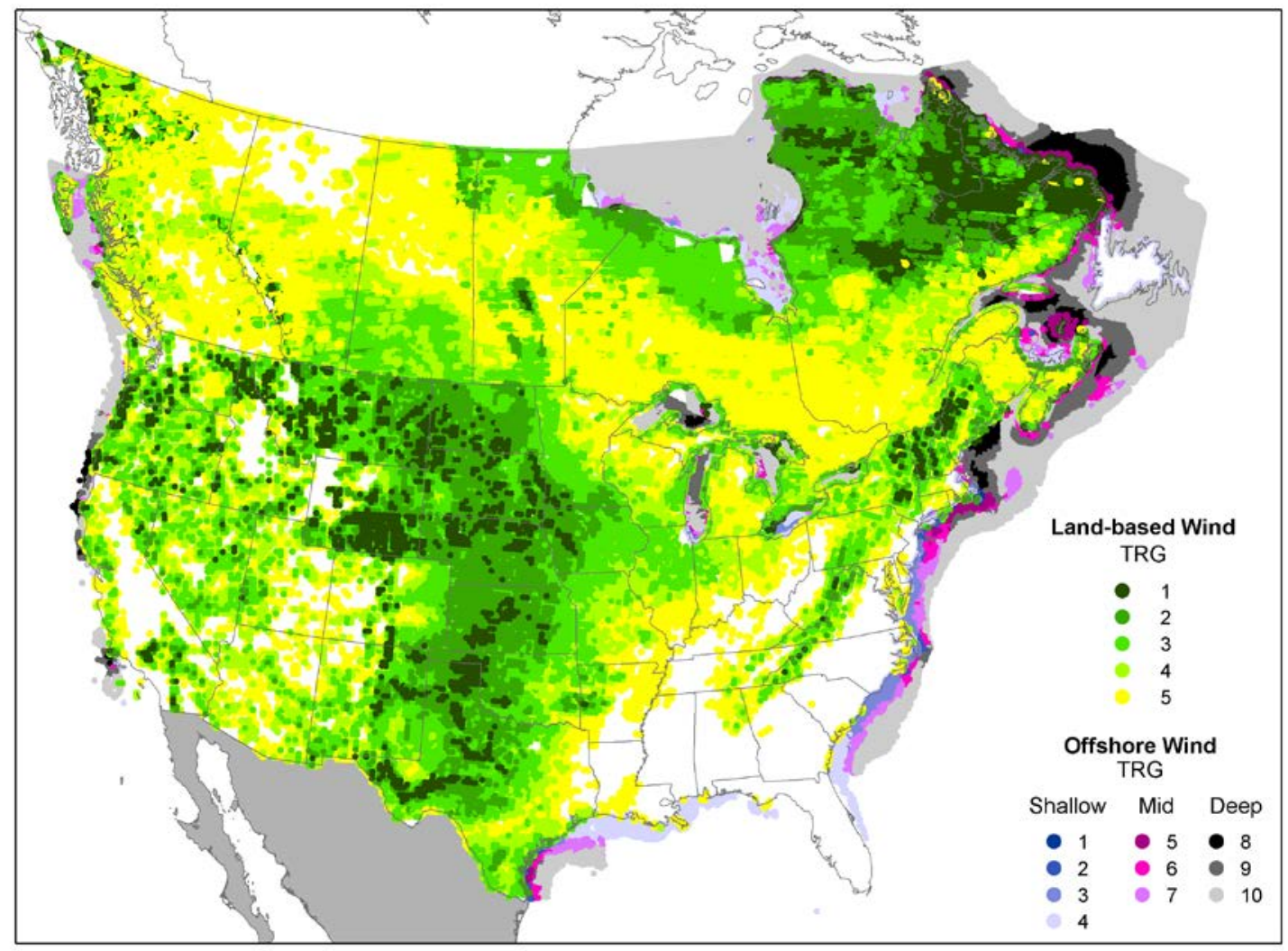

Figure 7. Wind resource location and classification in the United States and Canada

Note: Darker color indicates higher quality wind resource 
Table 1. Wind Potential by Country

\begin{tabular}{lccc}
\hline Country & $\begin{array}{c}\text { Onshore wind } \\
\text { potential (GW) }\end{array}$ & $\begin{array}{c}\text { Offshore wind } \\
\text { potential (GW) }\end{array}$ & $\begin{array}{c}\text { Total wind } \\
\text { potential (GW) }\end{array}$ \\
\hline United States & 6,169 & 1,560 & 7,729 \\
Canada & 7,854 & 13,259 & 21,114 \\
\hline
\end{tabular}

\subsubsection{Solar Representation}

Utility-scale photovoltaic (PV) cost and performance assumptions are based on NREL (2014). Solar insolation data is obtained from Canadian Weather year for Energy Calculation (CWEC) (2013), a data set comprising twelve typical meteorological months (derived from almost 30 years of data) from 80 weather stations throughout Canada (Environment Canada 2014). Average insolation data was then aggregated to the ReEDS BA level and applied in the System Advisor Model (SAM) to create hourly output profiles for a representative utility-scale PV plant ${ }^{10}$ (Blair et al. 2014). Hourly plant output from SAM is then aggregated to ReEDS time slice granularity and applied in the model. Average annual capacity factors for utility-scale PV systems are shown below in Figure 8.

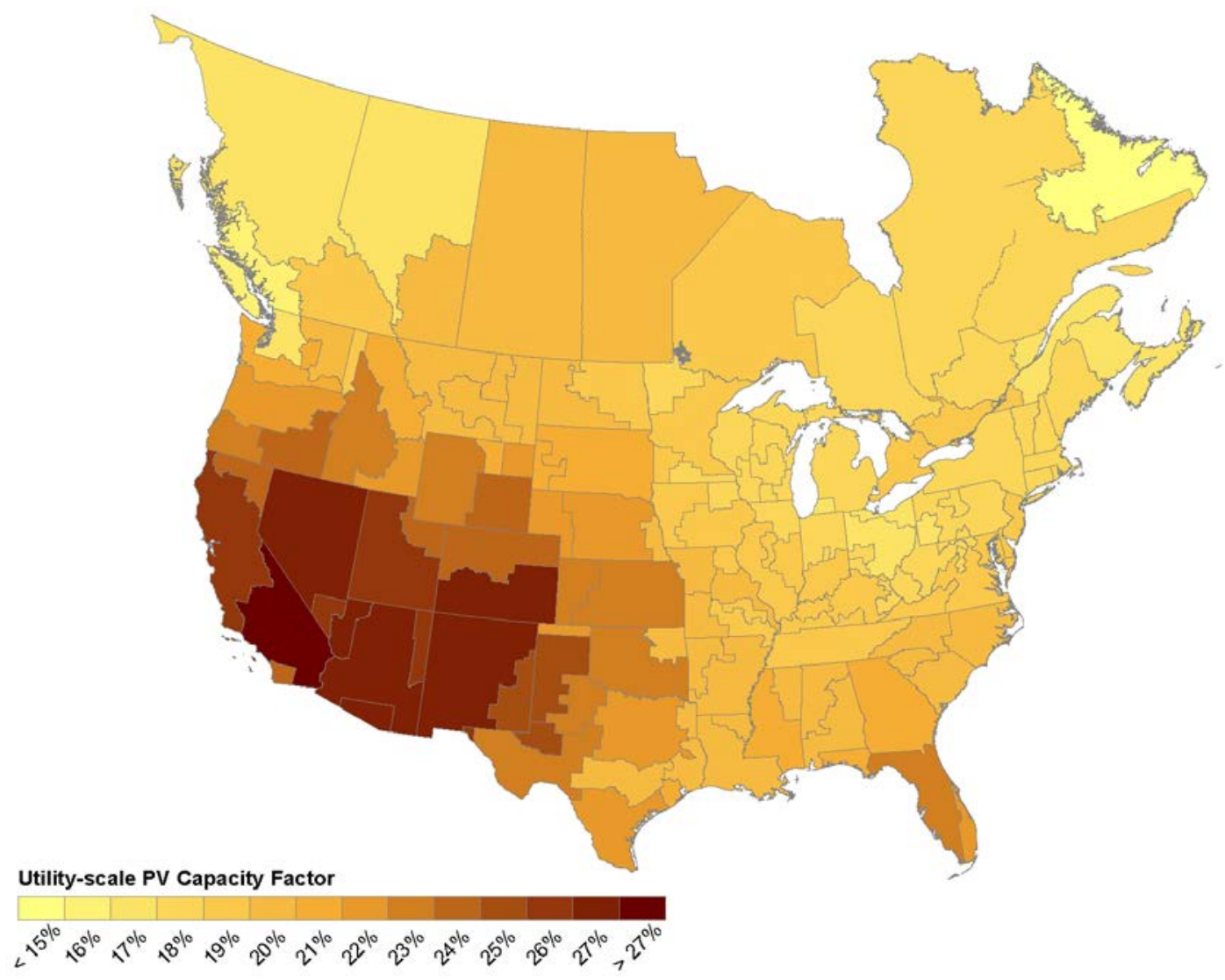

Figure 8. Average annual utility-scale PV capacity factors for ReEDS BAs

\footnotetext{
${ }^{10}$ For more information on the characteristics of this representative plant, see Short et al. (2011).
} 
The deployment of residential and commercial rooftop PV systems is exogenously defined in the ReEDS scenarios using output from NREL's Solar Deployment Systems (SolarDS) model (Denholm 2009). Because this model is not currently designed to capture consumer behavioral dynamics in Canada, we assume no rooftop PV deployment in Canada through the analysis period. Direct normal irradiance throughout Canada is below the threshold necessary to produce economic Concentrating Solar Power generation, and thus is not represented in Canada.

\subsubsection{Geothermal Representation}

We do not represent geothermal technologies in Canadian provinces due to a lack of sufficient information on the location and potential of geothermal resources. This could be the subject of future work.

\subsubsection{Biomass Representation}

Biomass can be used for electricity generation in a dedicated biopower plant or in a converted coal-fired plant that can co-fire biomass and coal. We represent dedicated biomass generation facilities consistently with EIA (2014). The biomass feedstock supply curve for each Canadian BA is assumed to be the same as that of the contiguous BAs in the United States (scaling to account in differences in area), consistent with Martinez et al. (2013). The biomass feedstock supply curves represent the quantity and associated price for a power plant to buy biomass to produce power. Future resource assessments for biomass feedstocks are needed to improve this representation.

\subsection{Policy and Regulation}

\subsubsection{State and Provincial RPS}

ReEDS represents all existing, mandatory state RPS. We model the impact of RPS programs in 28 U.S. states, the District of Columbia, Nova Scotia and British Columbia, including solar RPS carve-out requirements in 12 U.S. states. Each of the RPS requirements is assumed to be fully met unless an alternative compliance payment is endogenously selected to be made.

Renewable energy certificates (RECs) are represented as technology-specific in ReEDS, and can be purchased and retired across select states, as aligned with current laws, regulations and practices for interstate trading and RPS technology eligibility. Banking and borrowing of RECs between solve years is not modeled. All out-of-state REC purchases are required to be associated with delivered, technology-eligible renewable power.

Canadian contributions to U.S. state RPS (and vice versa) are permitted in alignment with existing laws, regulations and practices as of October 2014. We list the rules for U.S. - Canada REC trading in Table 2, focusing on U.S. states that are physically or electrically adjacent to a Canadian province, or where international REC trading activity has been observed in practice.

\subsubsection{Other State, Provincial, and Regional Electricity Policy}

The California Assembly Bill 32 Carbon Cap-and-Trade policy is also represented (CARB 2015). Electricity that is imported to California falls under the cap, and is attributed the average carbon intensity of the electricity on the importing transmission line. ReEDS does not include a representation of the Regional Greenhouse Gas Initiative (RGGI 2015). 
British Columbia has a carbon tax that is applied to in-province electricity generation (British Columbia Ministry of Finance 2015). This tax is also applied to imported electricity; in this case, the average carbon intensity of delivered electricity is endogenously calculated ${ }^{11}$ and taxed appropriately. We also implement the British Columbia 2016 requirement for electricity selfsufficiency $^{12}$ (Clean Energy Act 2010).

Table 2. International REC Trading Rules Implemented in ReEDS

\begin{tabular}{lll}
\hline State/Province & $\begin{array}{l}\text { Canadian RECs } \\
\text { Accepted? }\end{array}$ & Notes \\
\hline California & Yes & Power must be delivered to state \\
\hline Colorado & No & - \\
\hline Massachusetts & Yes & Power must be delivered to ISO-New England \\
\hline Maine & No & - \\
\hline Michigan & No & - \\
\hline Minnesota & Yes & Power must be delivered to state from Manitoba \\
\hline Montana & No & - \\
\hline Nevada & No & - \\
\hline New Hampshire & No & - \\
\hline New York & No & - \\
\hline Nova Scotia & Yes & RECs accepted from New England Power Pool \\
\hline Ohio & No & - \\
\hline Oregon & Yes & Subject to same bundling rules as U.S. states \\
\hline Pennsylvania & No & - \\
\hline Rhode Island & Yes & Power must be delivered to ISO-New England \\
\hline Washington & Yes & Power must be delivered to state \\
\hline Wisconsin & Yes & Power must be delivered to state \\
\hline
\end{tabular}

\subsubsection{National Electricity Policy}

Recent Environmental Protection Agency regulations, including the Cross-State Air Pollution Rule and Mercury and Air Toxic Standards are not modeled in this analysis. ${ }^{13}$ Nor are the impacts of proposed Environmental Protection Agency carbon pollution standard programs under Sections 111(b) (EPA 2014a) and 111(d) (EPA 2014b) of the Clean Air Act. However, the coal-fired unit retirement assumptions used in ReEDS includes announced near-term retirements (Saha 2013), which may be driven in part by pending or recently final U.S. Environmental Protection Agency (EPA) regulations.

\footnotetext{
${ }^{11}$ This calculation utilizes a proportional sharing construct adapted from Bialek (1996).

${ }^{12}$ The requirement is structured such that plants within British Columbia must generate as much energy as is required to serve load within the province.

${ }^{13}$ A sulfur dioxide cap based on the EPA Clean Air Interstate Rule is included for the contiguous United States.
} 
U.S. federal production and investment tax credits for RE are made available in U.S. regions. The wind production tax credit includes an "under construction" provision that allows for facilities that come online after 2014 to still quality for the $\$ 0.23 / \mathrm{kWh}$ tax credit ${ }^{14}$. This is addressed in ReEDS by the inclusion of plants that are under construction or with power purchase agreements from the American Wind Energy Association (AWEA 2014). The solar investment tax credit reduces from $30 \%$ of system capital costs to $10 \%$ at the end of 2016 , and the geothermal investment tax credit of $10 \%$ is modeled for all years.

\footnotetext{
${ }^{14}$ Expressed in 2013 U.S. dollars.
} 


\section{Description of Scenarios}

In order to demonstrate the capabilities of the tool, we model a series of scenarios that cover a wide range of possible U.S. - Canada power sector futures. The analysis portion of this work relies on the design of the reference scenario, as well as five sensitivity scenarios exploring a variety of conditions. The reference scenario is designed to serve as a point of comparison for the scenario suite.

This section presents first the key assumptions that characterize the reference scenario and then the list of scenarios considered. All scenarios use the model updates presented in Section 2 and the assumptions in the reference scenario, unless otherwise noted. Scenario analysis was conducted through the 2036 ReEDS solve year ${ }^{15}$ to mimic the time horizon in NEB (2013) which includes results through 2035.

None of the assumptions made - in the reference scenario or sensitivities - are intended to reflect predictions of future technology or market conditions. Rather, the scenarios are designed to assess a reasonable range of future conditions.

\subsection{Key Reference Scenario Assumptions}

Table 3 summarizes the underlying input assumptions of the reference scenario, all of which are described in greater detail in Section 2.

Table 3. Key Reference Scenario Assumptions for Canada

\begin{tabular}{|c|c|}
\hline \multicolumn{2}{|r|}{ Electricity Demand } \\
\hline Load Shapes & Provincial and zonal load shapes consistent with Martinez et al. (2013) \\
\hline Annual Demand Projections & Provincial projections from NEB (2013) \\
\hline Natural Gas & $\begin{array}{l}\text { Regional pricing from AEO } 2014 \text { Reference Scenario (EIA 2014) and } \\
\text { NEB (2013) }\end{array}$ \\
\hline Coal & Provincial prices from NEB (2013) \\
\hline Nuclear Fuel & National Prices from EIA (2014) \\
\hline & Technology Cost and Performance \\
\hline Conventional Generation & AEO 2014 Reference Scenario (EIA 2014) \\
\hline Wind and Solar & NREL (2014) \\
\hline \multicolumn{2}{|r|}{ Infrastructure } \\
\hline Transmission & Consistent with Martinez et al. 2013 \\
\hline $\begin{array}{l}\text { Existing Capacity, } \\
\text { Expected Retirements and } \\
\text { New Infrastructure }\end{array}$ & Ventyx Energy (2014), NEB (2013) and OME (2013) \\
\hline
\end{tabular}

\footnotetext{
${ }^{15}$ ReEDS simulates the capacity expansion of the power system in two year increments and can model scenarios out to 2050 .
} 


\subsection{Scenario Matrix}

Six scenarios are analyzed, as summarized in Table 4. The reference scenario ("BaseCase") uses all assumptions listed in Section 2 and the previous subsection. The remaining scenarios explore the impact of modifying various input assumptions, and form the study sensitivity suite. These sensitivities are clustered into three groups to structure the analysis.

Table 4. List of Analysis Scenarios

\begin{tabular}{lll}
\hline Scenario Code & Scenario Description & Sensitivity Group \\
\hline BaseCase & Reference & - \\
\hline HiGas & $\begin{array}{l}\text { High Natural Gas Price } \\
\text { (AEO 2014 Low Oil \&Gas Resource Case [EIA 2014]) }\end{array}$ & Natural gas \\
LoGas & $\begin{array}{l}\text { Low Natural Gas Price } \\
\text { (AEO 2014 High Oil \& Gas Resource Case [EIA 2014]) }\end{array}$ & \\
\hline SeparateRE & $\begin{array}{l}\text { Separate U.S. and Canada RE Requirement } \\
60 \% \text { energy by 2036 }\end{array}$ & High RE \\
JointRE & $\begin{array}{l}\text { Joint U.S. and Canada RE Requirement } \\
60 \% \text { energy by 2036 }\end{array}$ & $\begin{array}{l}\text { Canadian } \\
\text { hydropower }\end{array}$ \\
\hline HiCanHydro & $\begin{array}{l}\text { Canadian hydro capacity increases } \\
\text { 15 GW by 2035 }\end{array}$ &
\end{tabular}

The first group corresponds to natural gas price sensitivities, with a high natural gas price scenario ("HiGas") and a low natural gas price scenario ("LoGas"). The only difference between these scenarios and the "BaseCase" scenario is the use of a different natural gas price projection, more specifically using the "Low Oil \& Gas Resource" for HiGas and "High Oil \& Gas Resource" for LoGas from AEO 2014 (EIA 2014), respectively. Figure 9 depicts the AEO 2014 natural gas price projections, by EIA Census Region, ${ }^{16}$ for the Reference, Low O\&G Resource and High O\&G Resource cases.

The second group of sensitivities presents a prescribed RE requirement, that is, RE must serve an increasing fraction of load. This requirement mimics the prescribed trajectories in NREL's Renewable Electricity Futures study (NREL 2012), reaching 60\% of substation-level demand by $\mathrm{RE}$ in the year 2036. The first scenario in this sensitivity group forces the United States and Canada to follow the RE prescription independently ("SeparateRE"). In other words, the United States and Canada must meet discrete, unconnected national targets for RE using only their domestic resources and explicitly excluding imports. The second scenarios imposes a single RE requirement over both countries ("JointRE"), thus encouraging cooperation and an integrated approach to meeting the requirement. In both cases the RE requirements includes hydropower, wind, solar PV and CSP, geothermal and biopower.

\footnotetext{
${ }^{16}$ Refer to Figure 2 for the Census boundaries, as utilized in ReEDS.
} 


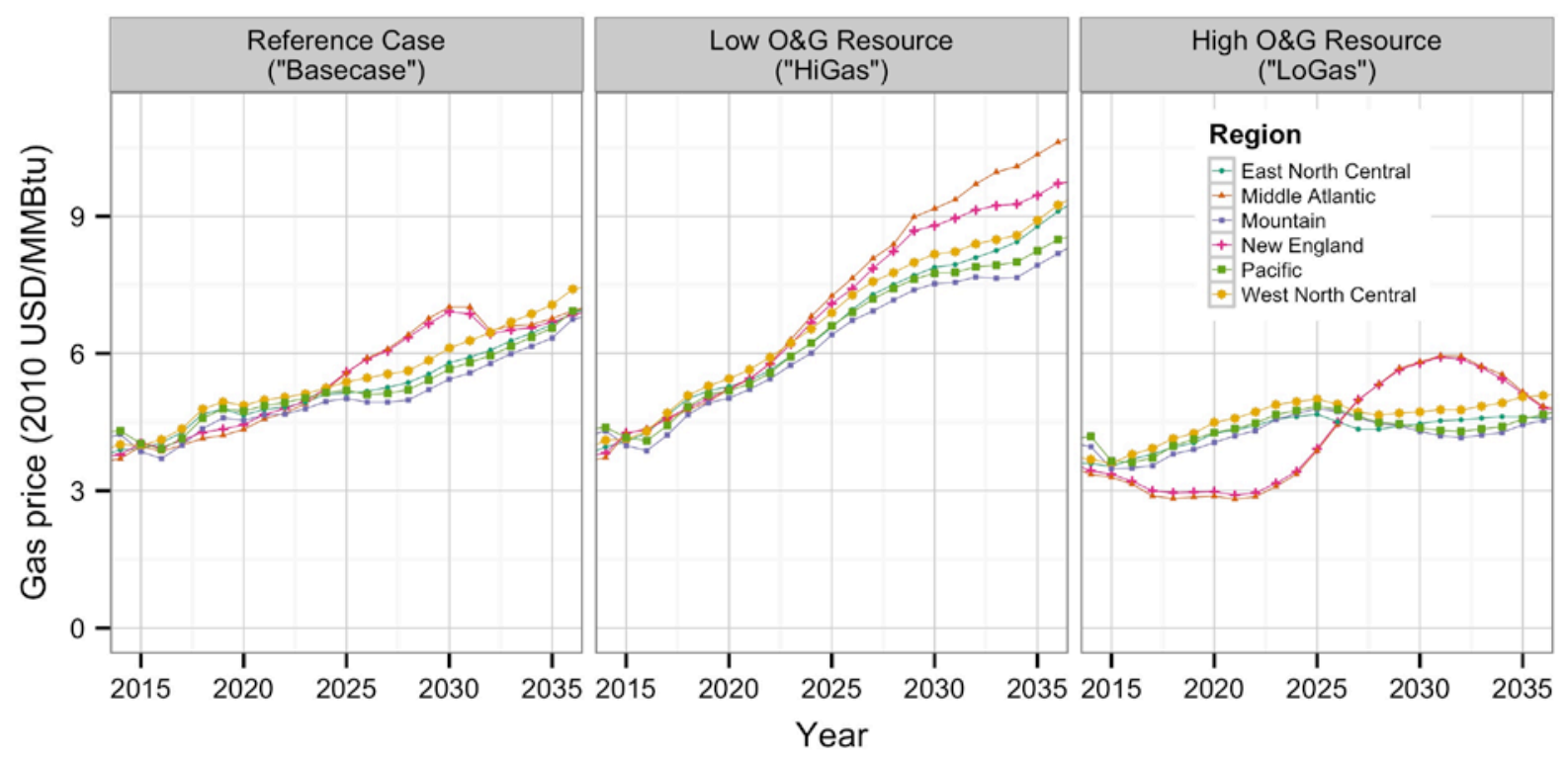

Figure 9. Natural gas price forecasts from AEO 2014 for the gas sensitivities

The final scenario presents a case with higher deployment of conventional hydropower capacity in Canada through 2036 ("HiCanHydro") relative to the "BaseCase" scenario. Given the lack of available data to formulate a supply curve and appropriately represent the hydropower potential in Canada within the ReEDS framework, the "BaseCase" scenario enforces hydropower expansion in Canada, based on data from NEB (2013). The "HiCanHydro" scenario presents a more aggressive hydropower deployment scenario, which reaches $87 \mathrm{GW}$ of cumulative Canadian hydropower capacity by 2036 compared to $81 \mathrm{GW}$ in the "BaseCase" scenario. 


\section{Sample Model Results}

This section summarizes the results from the analysis framework described in Section 3. We begin by analyzing the "BaseCase" scenario results in detail and then explore the key insights derived from the sensitivity analysis. These scenarios are intended to serve as an exercise to explore model capabilities and obtain an augmented understanding of the drivers behind its leastcost decision-making behavior when input assumptions are perturbed.

\subsection{Reference Scenario Results}

This section describes the results of the "BaseCase" scenario. We begin by describing the evolution of the U.S. and Canadian capacity (Figure 10) and generation (Figure 11) mix $^{17}$. Given the cost and performance assumptions utilized and state RPS requirements, we observe a significant growth of wind and solar PV deployment in the United States, reaching $181 \mathrm{GW}$ and $168 \mathrm{GW}$, respectively. There is also a reduction in nuclear (from $98 \mathrm{GW}$ to $68 \mathrm{GW}$ ), coal (from $296 \mathrm{GW}$ to $229 \mathrm{GW}$ ) and oil-gas-steam (OGS) (from $83 \mathrm{GW}$ to $5 \mathrm{GW}$ )) generation capacity driven by prescribed and lifetime retirements that do not get rebuilt. There is a moderate increase in natural gas CC capacity from $(220 \mathrm{GW}$ to $231 \mathrm{GW})$ and a more significant increase in natural gas combined turbine (CT) capacity (from $145 \mathrm{GW}$ to $320 \mathrm{GW}$ ). CT generators are primarily utilized to meet planning capacity reserve margins.

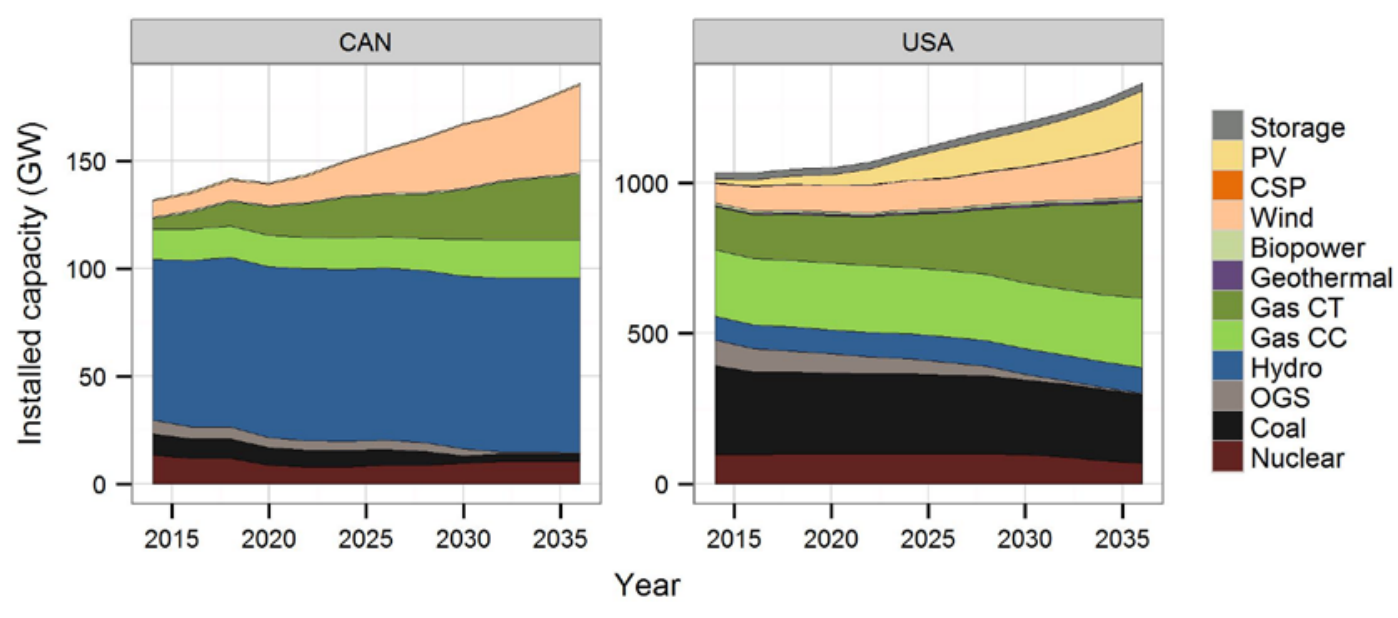

Figure 10. Capacity by generator type for the United States and Canada, "BaseCase" scenario

The capacity mix in Canada follows a similar evolution. There is a gradual decline of nuclear ${ }^{18}$ (from $14 \mathrm{GW}$ to $10 \mathrm{GW}$ ), coal (from $10 \mathrm{GW}$ to $4 \mathrm{GW}$ ) and OGS (from $6 \mathrm{GW}$ to $0.6 \mathrm{GW}$ ) capacity, mainly due to prescribed retirements. Hydropower ${ }^{19}$ and gas $\mathrm{CC}$ capacity increases slightly (6 GW and $4 \mathrm{GW}$, respectively), whereas wind power experiences significant growth (just over $33 \mathrm{GW}$ ) and is used to meet the majority of future load growth (Figure 12). Again, the

\footnotetext{
${ }^{17}$ Note that many figures in this section use different vertical scales for United States and Canadian results, if necessary.

${ }^{18}$ A portion of the loss of nuclear capacity is restored within the simulation horizon as existing units are placed back online following refurbishment.

${ }^{19}$ Hydropower capacity expansion is prescribed in this study, as previously described.
} 
significant contribution of wind to new capacity additions is largely driven by the cost and performance assumptions for the different generation technologies.

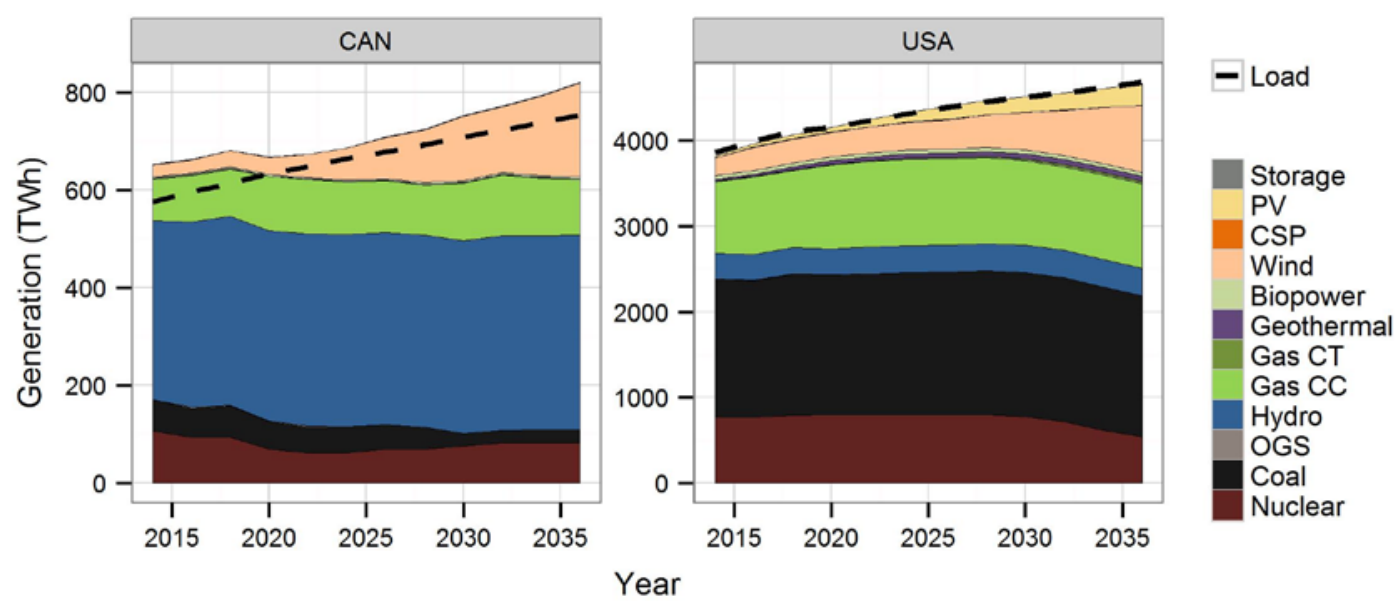

Figure 11. Generation by type for the United States and Canada, "BaseCase" scenario

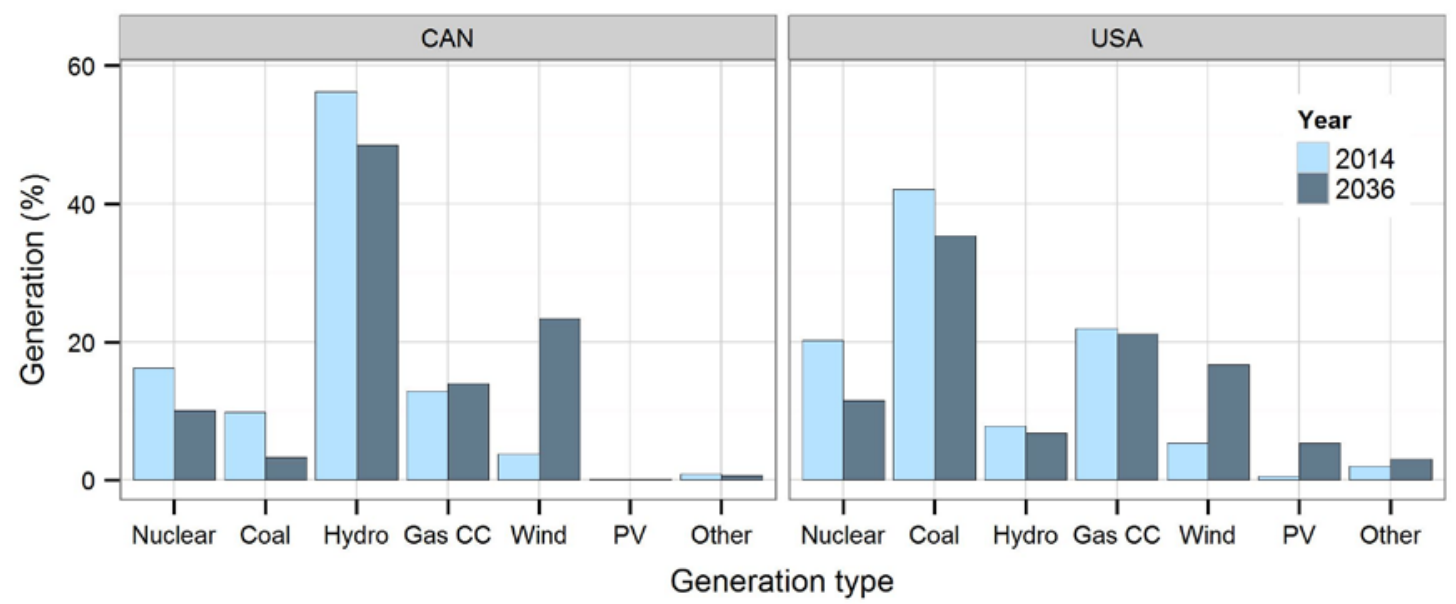

Figure 12. Breakdown of generation by country for the beginning and the end of the simulation, "BaseCase" scenario

Figure 13 presents the breakdown by province of the significant wind deployment experienced in Canada and presented in the previous figures. While the growth in wind deployment is spread across all Canadian provinces, much of the capacity is concentrated in Quebec and Alberta, the regions with the largest absolute load growth and highest quality wind resource. Quebec is a net exporter of electricity to the United States throughout the simulation. 


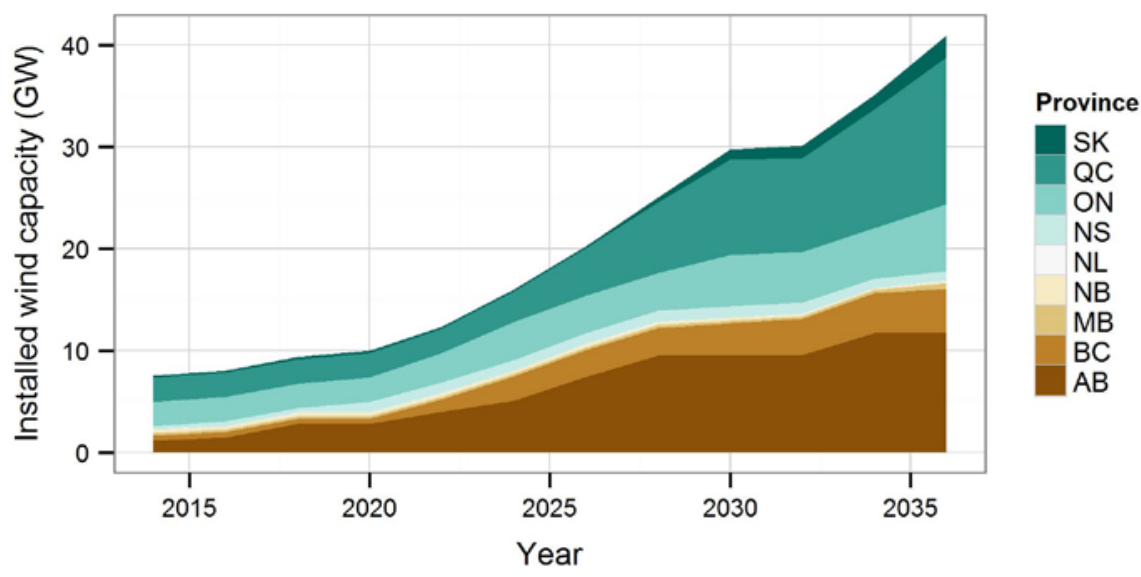

Figure 13. Wind capacity growth by Canadian provinces, "BaseCase" scenario

Figure 11 includes, along with generation, a line that shows the total electricity demand by country. The difference between total generation and electricity demand corresponds to the interchange between the countries, which is also presented in Figure 14. The figure shows that net imports to the United States from Canada remain positive throughout the analysis period, although the magnitude varies. In the first half of the time horizon, the net interchange is reduced gradually as Canadian conventional generators are retired at a faster pace than new plants are installed, and natural gas generators on the U.S. border that initially had low capacity factors are ramped up to meet this new demand. In the last 10 years of the simulation, the net interchange increases again as prescribed retirements are less severe and more Canadian hydropower and wind capacity is installed. For comparison purposes, the net interchanges presented in NEB (2013) are typically in the 40-50 TWh range annually for the same timeframe.

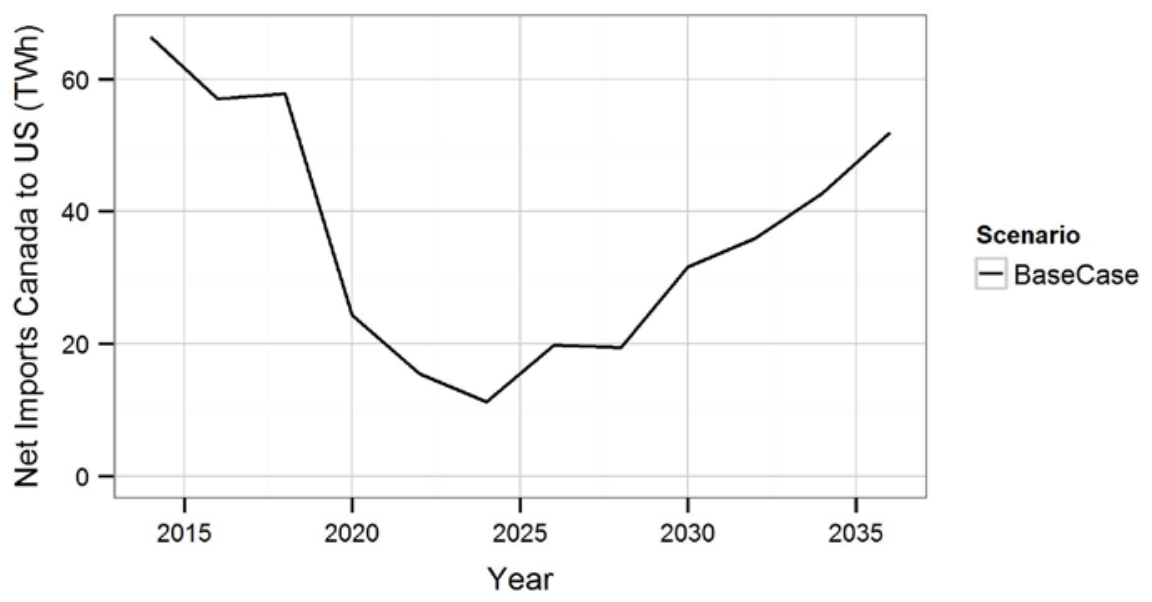

Figure 14. Net energy interchange between Canada and the United States, "BaseCase" scenario

Figure 15 shows the breakdown of net interchange by "zones" across the border. In the east, ISO New England (ISO-NE) and New York ISO (NYISO) import energy throughout the entire study period through 2036, with NYISO increasing that share in the later simulation years. However, in the Western Interconnection we see increasing net imports to Canada from the United States, mainly driven by the rapid load growth in Alberta, which is satisfied partially by U.S. generation. 
In the Midcontinent ISO (MISO) we initially observe imports from Canada that reverse direction around 2026 and thereafter net to nearly zero. This is partially driven by early nuclear retirements in Ontario (which are later replaced by new capacity), modest wind deployment in Ontario and existing unused gas CC capacity in the United States, along with ample transmission capacity.

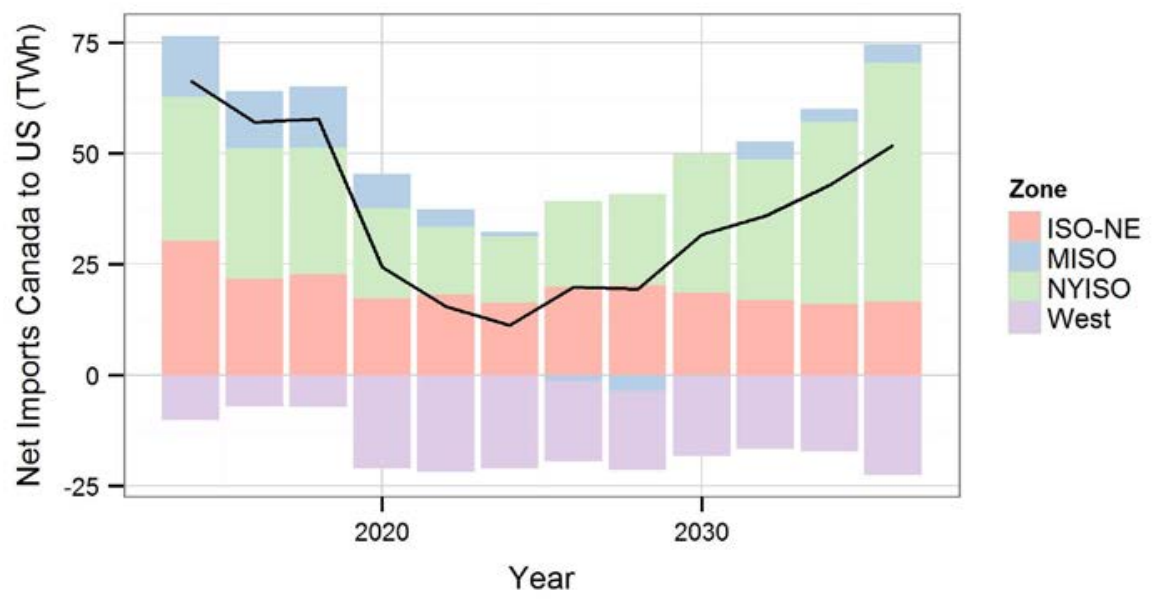

Figure 15. Net energy interchange between countries (line) along with net interchange by zone (bars), "BaseCase" scenario

To support this dynamic exchange of energy, model results indicate additional transmission capacity is needed. Figure 16 summarizes the total installed transmission capacity across the U.S.-Canada border, which nearly doubles within the analysis period.

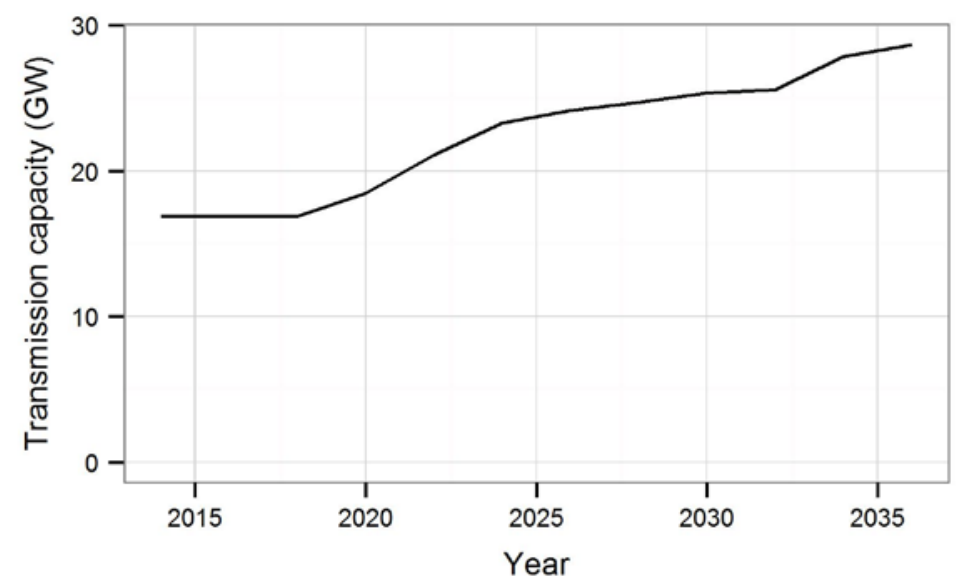

Figure 16. Transmission capacity across the U.S. - Canada border, "BaseCase" scenario

Figure 17 summarizes the locations where ReEDS builds new interregional AC transmission throughout the analysis period. Much of the new transmission construction occurs in the west (to enable increased levels of power export to Alberta), followed by new transmission lines into NYISO. There is also a marginal increase of transmission capacity into MISO. 


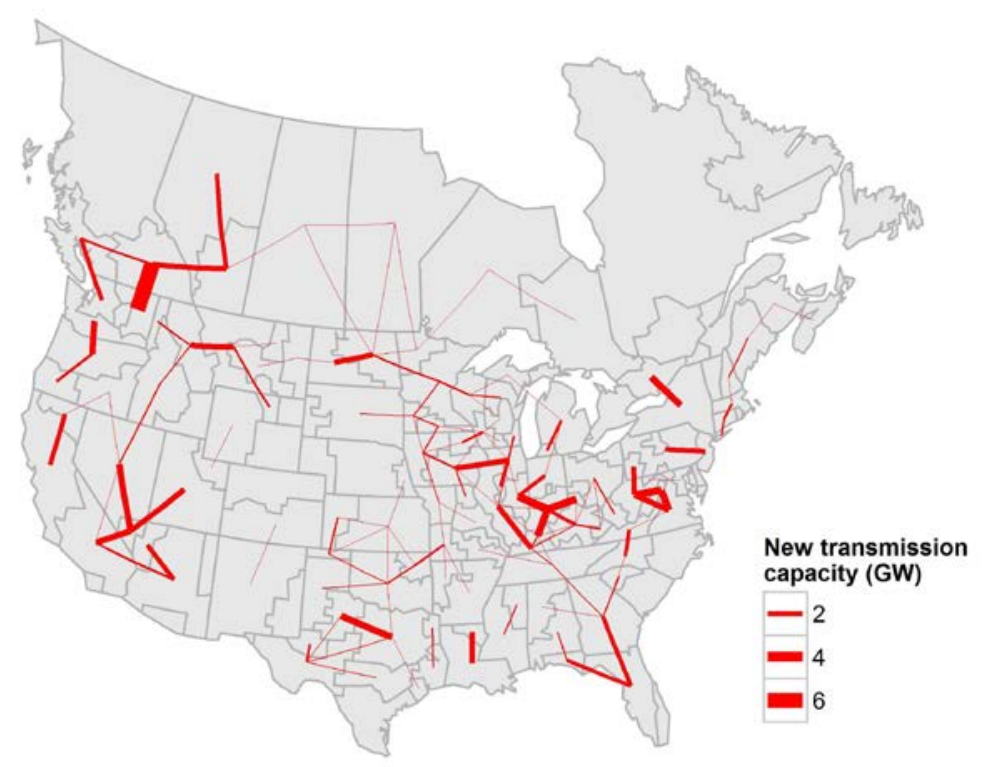

Figure 17. New transmission investments between ReEDS BAs, "BaseCase" scenario by 2036

Transmission is utilized not only to transfer energy, but also firm capacity. ReEDS simulates and optimizes the energy and firm capacity exchange regions simultaneously. While energy interchange is used complementarily to meet demand on either side of the border, firm capacity transfers contribute to meeting reserve margins. Figure 18 illustrates how the net interchange of firm capacity evolves over time.

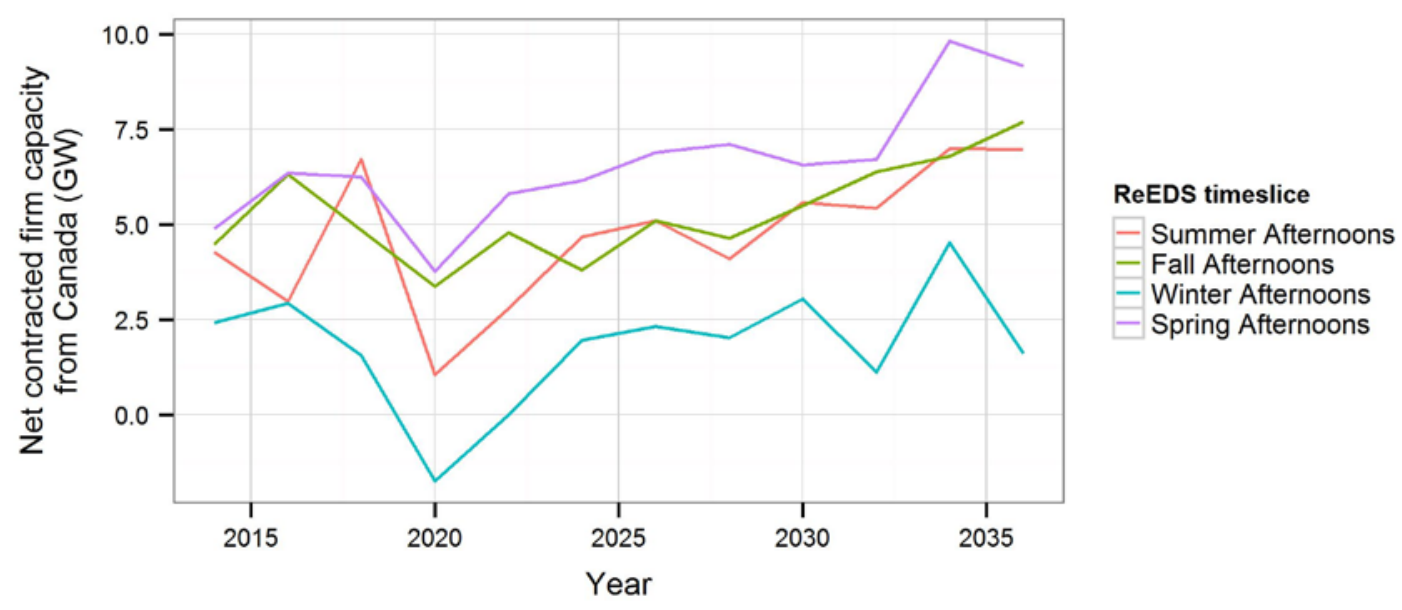

Figure 18. Net firm capacity exchange between countries, "BaseCase" scenario

Retail electricity prices in both the United States and Canada increase moderately for the duration of the simulation (Figure 19, left). Electricity prices in Canada are lower, primarily because of the dominance of hydropower. Similarly, there is an increase in natural gas prices (Figure 19, right). As discussed in Section 2, natural gas prices are elastic and, thus, prices depend on the level of demand. 

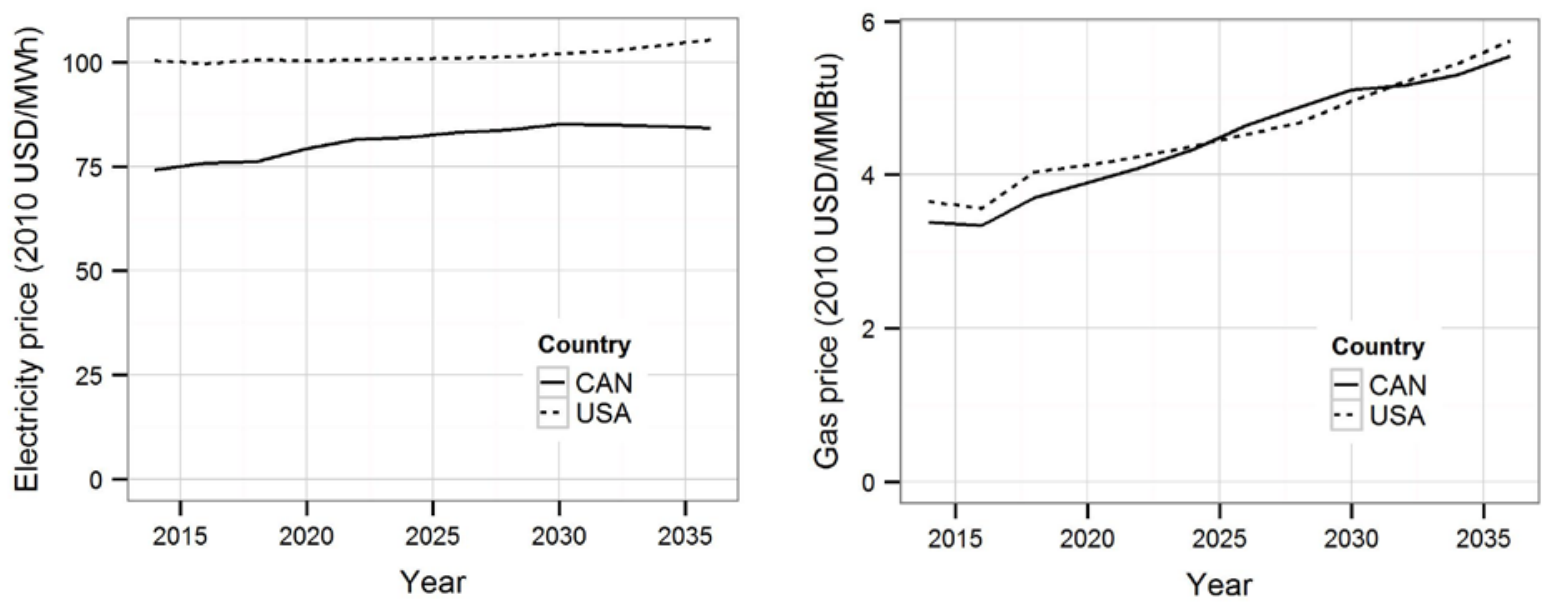

Figure 19. National average electricity (left) and natural gas (right) prices for Canada and the United States, "BaseCase" scenario

Finally, $\mathrm{CO}_{2}$ emissions behave differently in the two countries. Emissions in the United States are nearly flat over the analysis period at about 2 gigatonnes annually, while $\mathrm{CO}_{2}$ emissions decrease in Canada (Figure 20, left). The $\mathrm{CO}_{2}$ intensity in both countries decreases for the span of the simulation (Figure 20, right). This is consistent with the increase in generation share from renewables and natural gas, particularly wind and hydropower. $\mathrm{CO}_{2}$ intensity is lower in Canada than the United States due to the large share of hydro generation in the latter.
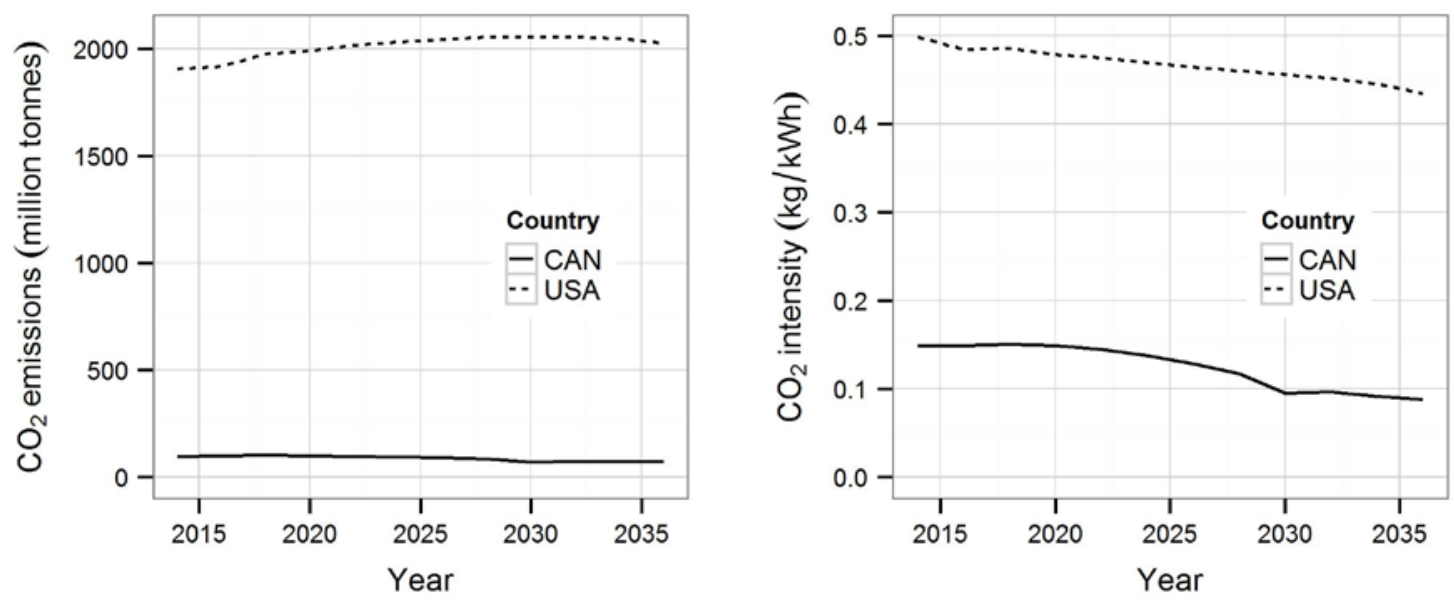

Figure 20. $\mathrm{CO}_{2}$ emissions (left) and average $\mathrm{CO}_{2}$ intensity by country, "BaseCase" scenario

\subsection{Natural Gas Price Sensitivities}

Figure 21 shows the combined United States and Canadian average natural gas output prices for the sensitivities presented in this section. ${ }^{20}$

\footnotetext{
${ }^{20}$ Natural gas prices differ regionally based on the projections shown in Figure 9.
} 


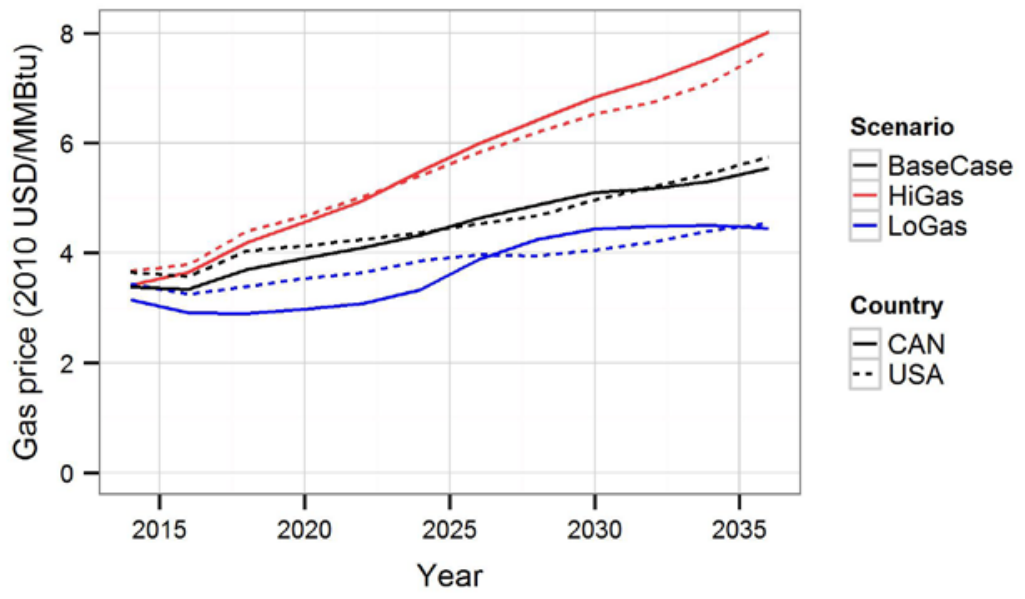

Figure 21. United States and Canadian average natural gas prices for the natural gas sensitivities

Perturbing natural gas prices has a noticeable effect on modeled results. The "HiGas" scenario sees a general increase in wind capacity in Canada and the United States, along with some additional solar in the United States (see Figure 22). There is a marginal decrease in gas CC and gas CT deployment in both countries, though gas CC generators in both countries are ramped down (see Figure 23). Additionally, there is a slight increase in generation from U.S. coal in the middle simulation years.

The "LoGas" scenario shows the opposite trend. In both the United States and Canada, there is an increase in gas CC deployment, which primarily displaces wind and gas CT capacity. There is also a small decrease in coal capacity and generation in both countries relative to the "BaseCase" scenario.

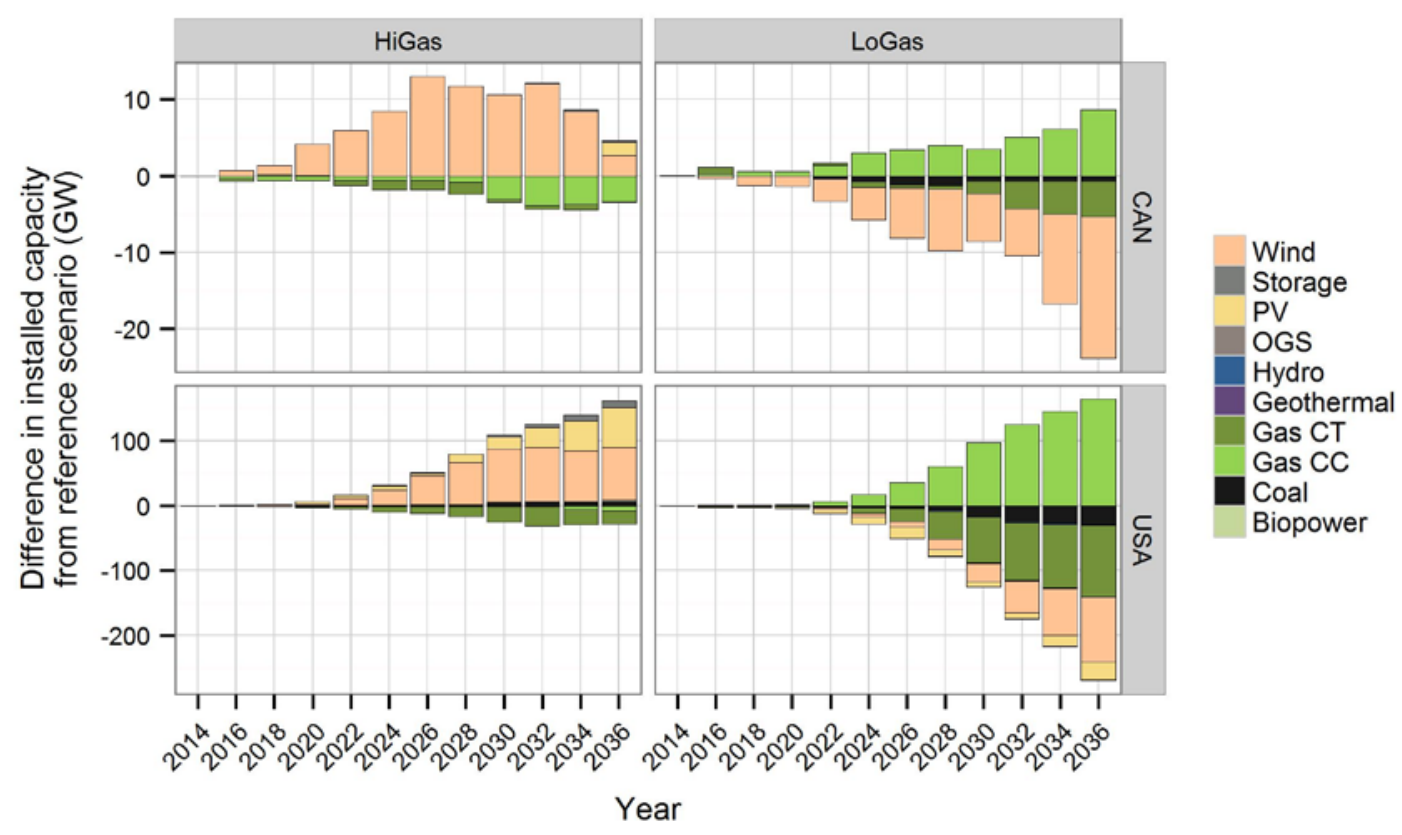

Figure 22. Change in capacity for natural gas sensitivities, compared to "BaseCase" scenario 


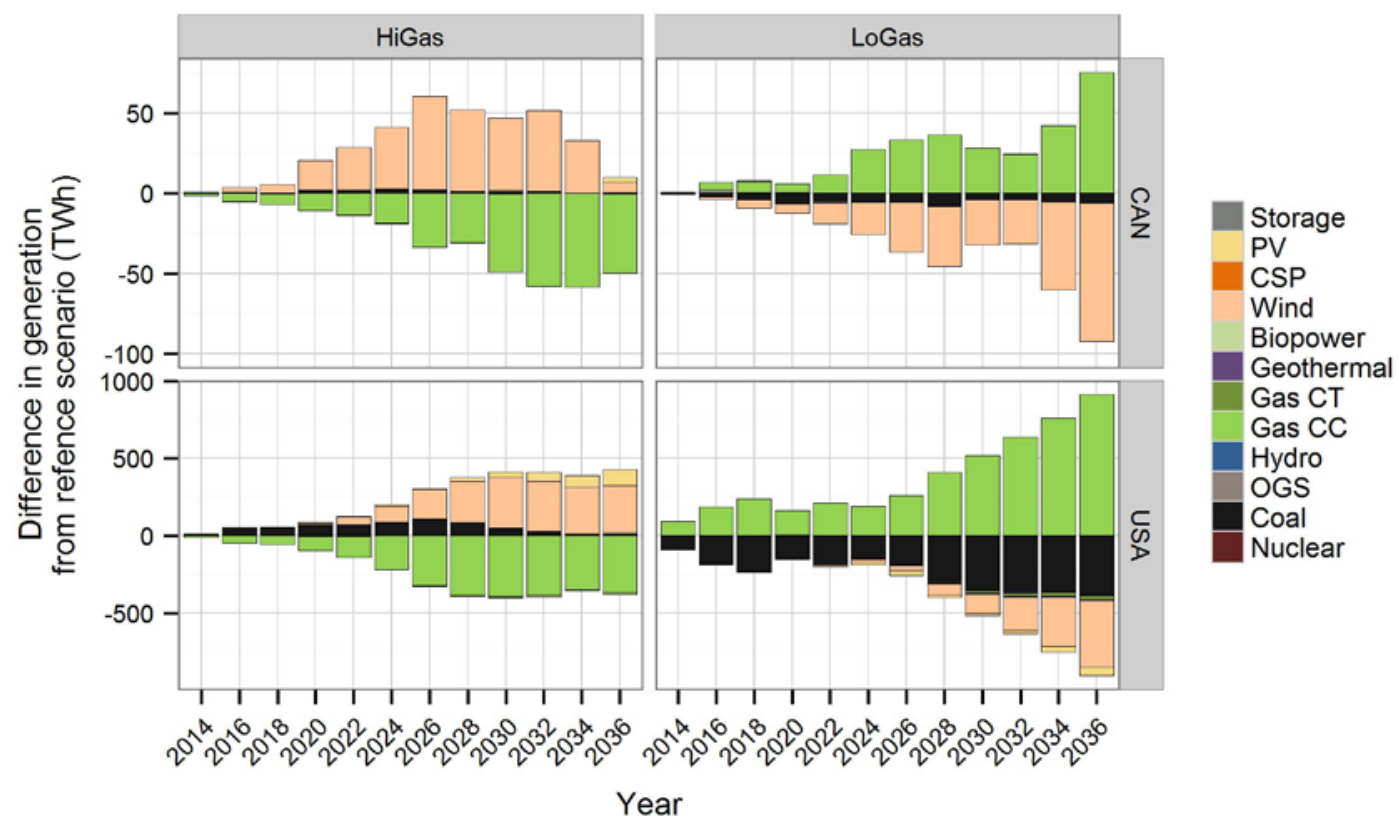

Figure 23. Change in generation for natural gas sensitivities, compared to "BaseCase" scenario

Figure 23 shows that the generation perturbations are not necessarily balanced for each country. Thus, the net energy interchange varies from the "BaseCase" scenario, as shown in Figure 24. The "LoGas" scenario shows a pattern of net interchange similar to the "BaseCase" scenario and is slightly smaller in the later years. The "HiGas" scenario presents a more pronounced deviation, with increases in net imports relative to the "BaseCase" scenario in early years, and lower net imports in latter years. These results reflect regional differences in net imports further explored below.

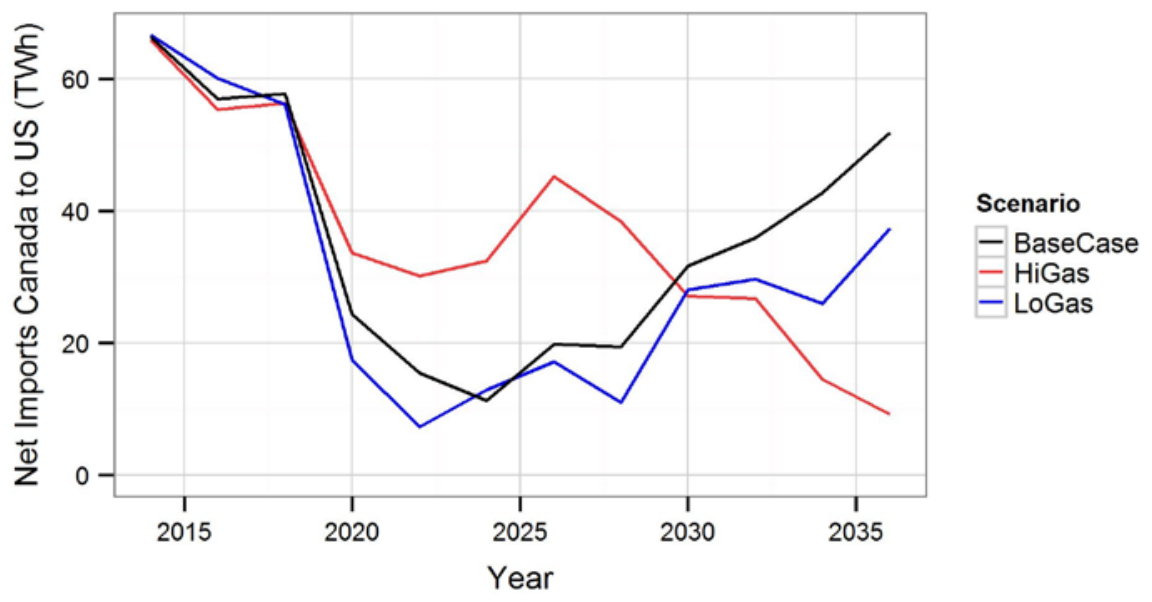

Figure 24. Net energy interchange between countries for the natural gas sensitivities

Figure 25 shows the evolution of zonal net interchanges, which are driven by regional differences in natural gas price (Figure 9). The largest deviations from the "BaseCase" scenario for both "HiGas" and "LoGas" - happen in the West and New England zones. For the "HiGas" 
scenario, net imports from Canada are largely driven by export behavior from the Western United States into Canada. In the early years, U.S. exports to Canada from the West decrease relative to the "BaseCase" scenario. In the later years, these exports significantly increase. For the "LoGas" scenario, the net import behavior is relatively similar to the "BaseCase" scenario, with most of the deviations primarily due to decreases in imports to ISO-NE from neighboring Canadian provinces.

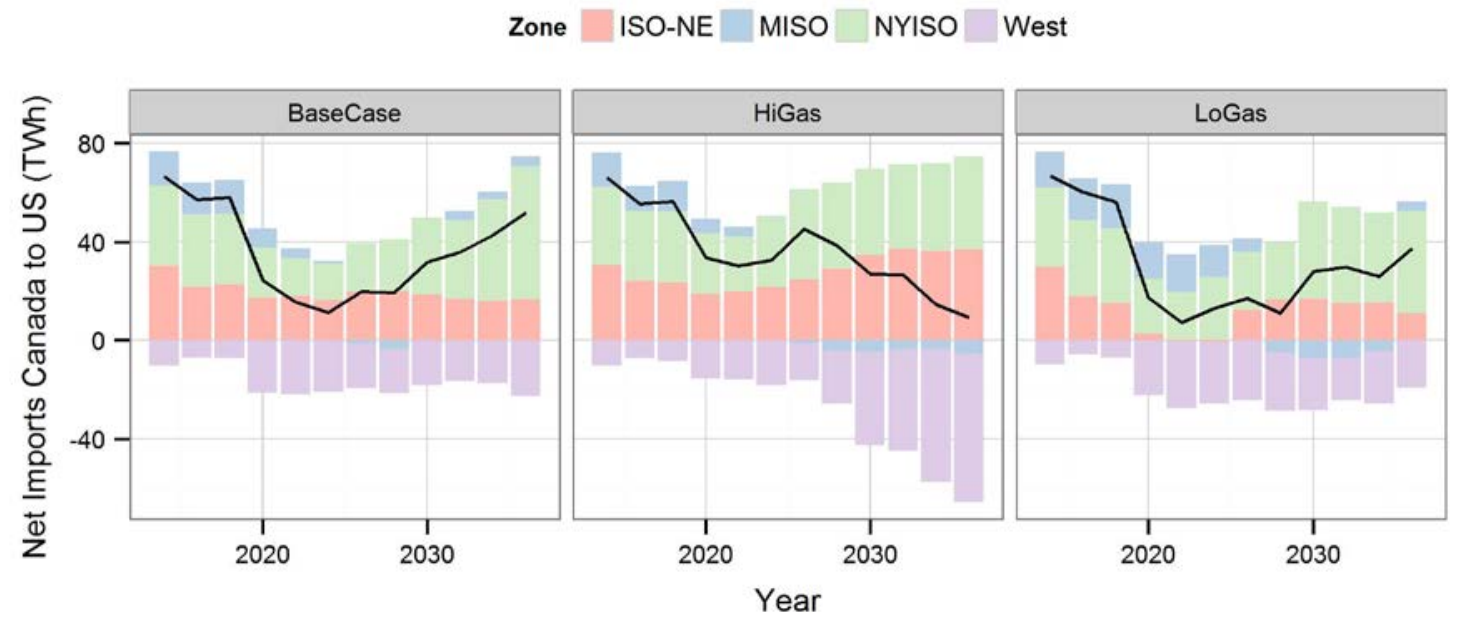

Figure 25. Net energy interchange between countries (line) along with net interchange by zone (bars) for the natural gas sensitivities

To better understand the drivers behind this behavior, Figure 26 illustrates gas $\mathrm{CC}$ and wind generation by scenario for the Canadian provinces and U.S. states along the border. Gas CC and wind technologies are strongly affected by natural gas price perturbations in the model, as they often compete with one another for deployment.

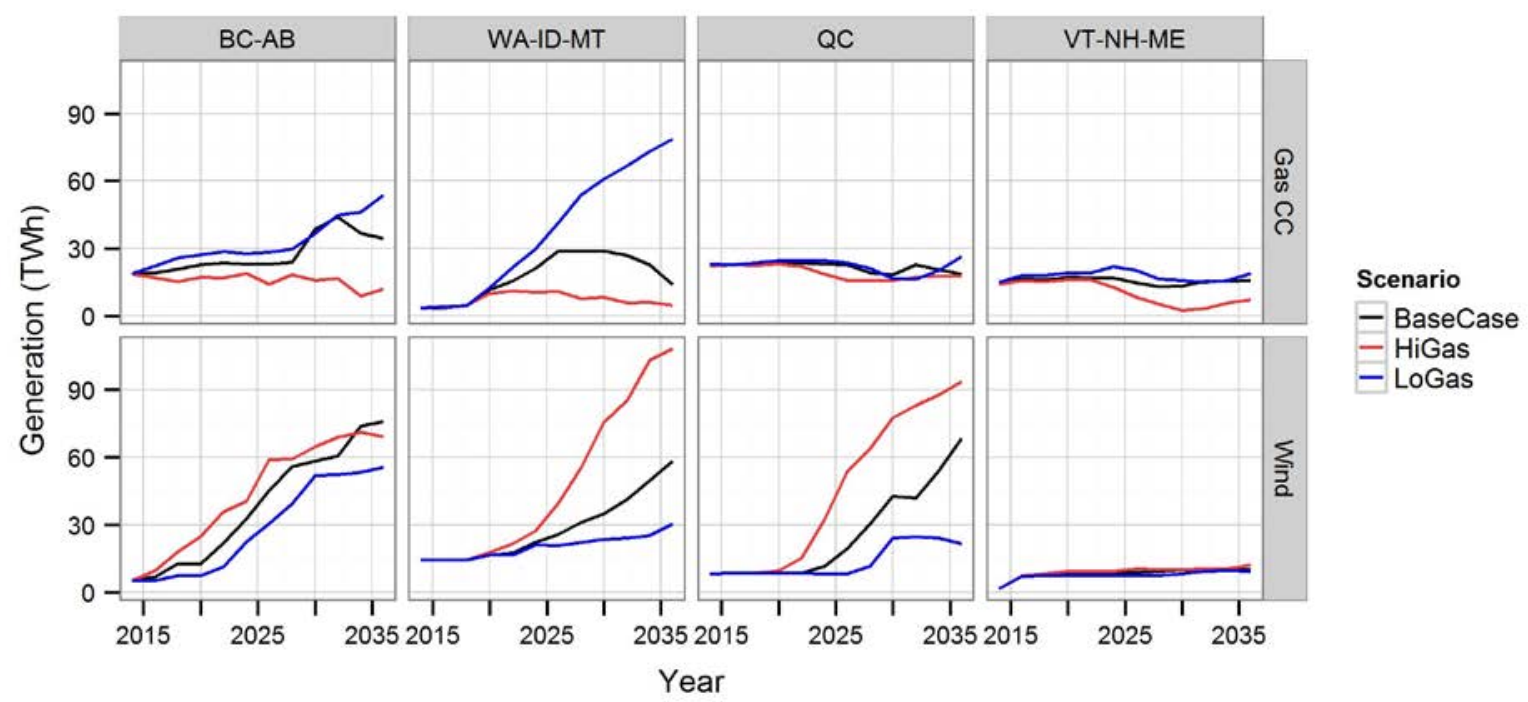

Figure 26. Comparison of gas $\mathrm{CC}$ and wind generation for the natural gas sensitivities in selected states and provinces 
In the Western Interconnection, we observe net exports from the United States into Canada under all scenarios. The "HiGas" scenario sees an accelerated deployment of wind in British Columbia and Alberta, which drives the lower overall net exports into the United States in early years relative to the "BaseCase". The wind growth slows down in 2026, around the same time that U.S. wind installations accelerate in the Northwest (most notably in Montana). This wind growth pattern, along with the relatively flat generation from gas $\mathrm{CC}$ sources creates an increase in exports from the United States into Canada in the West.

Conversely, in the "LoGas" scenario, we observe a reduction of wind deployment, most noticeably in the United States. British Columbia and Alberta still experience growth in wind capacity to serve increasing load in Alberta, given the quality of the available wind resource in the area. This growth is smaller than in the "BaseCase" scenario, and gas CC units are installed in Washington to complement this deficit.

In the New England area, the story is remarkably different. Net imports to ISO-NE from Quebec are observed under all scenarios. The primary driver behind the magnitude of those imports is wind deployment in Quebec, where a significant economical wind resource base exists. In the "HiGas" scenario, wind in Quebec deploys faster and in larger volumes relative to the "BaseCase" scenario, displacing some gas CC generation in the United States and increasing the imports into ISO-NE. Under the "LoGas" scenario, the opposite is true: less wind capacity in Quebec deployed through the analysis period, resulting in reduced imports to ISO-NE relative to the "BaseCase".

The two gas sensitivity scenarios see similar transmission builds, comparable to that of the "BaseCase" scenario (Figure 27).

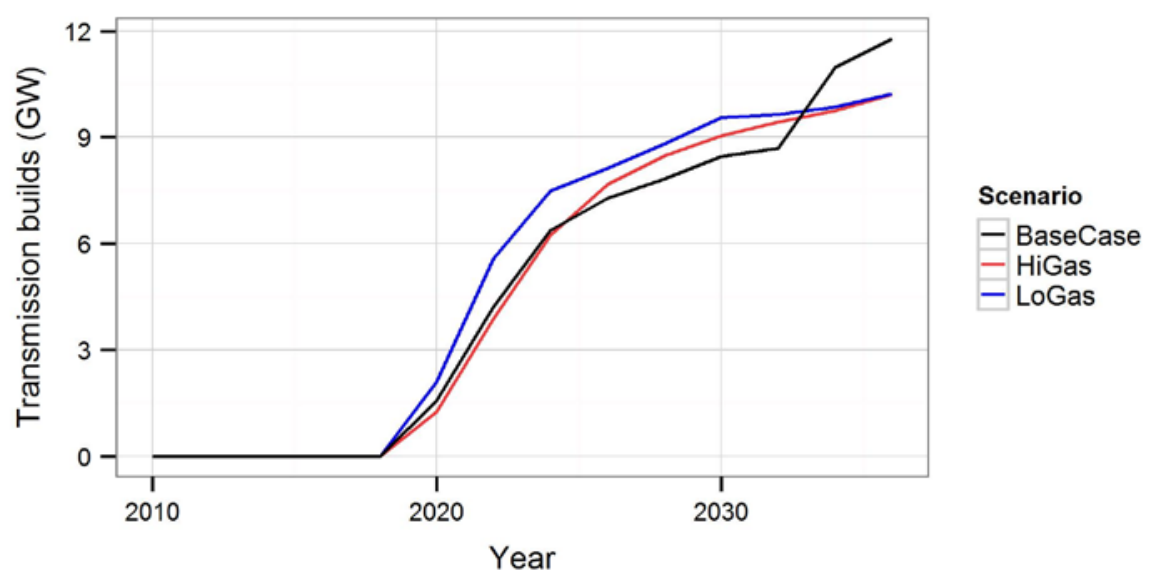

Figure 27. New international transmission capacity for natural gas sensitivities 


\subsection{High RE Penetration Sensitivities}

This section explores the differences between the reference scenario and the two sensitivities with high RE penetrations, "JointRE" and "SeparateRE". The prescribed trajectory is similar to that used in (NREL 2012), with $60 \%$ of total generation being produced by RE in 2036 . The "SeparateRE" scenario requires that the United States and Canada meet distinct, unconnected RE requirements using only their domestic renewable resource bases to comply, while for the "JointRE" there is a single international requirement for both countries, allowing compliance with the requirement using the best available renewable resources across both countries toward a single goal. In both scenarios the RE requirements includes hydropower, wind, solar PV and CSP, geothermal and biopower.

To contextualize results, Figure 28 illustrates the required RE generation trajectory, as well as the "BaseCase" scenario RE generation results for the United States and Canada. As the graph shows, the requirement is already met for Canada for the entire temporal span of the "BaseCase" scenario, and the requirement becomes binding in the United States in 2022 for the "SeparateRE" scenario. It is at this point that deviations from business-as-usual "BaseCase" behavior are observed. The figure also illustrates the combined country RE generation percentage. In the "JointRE" scenario, the RE requirement becomes binding in 2026.

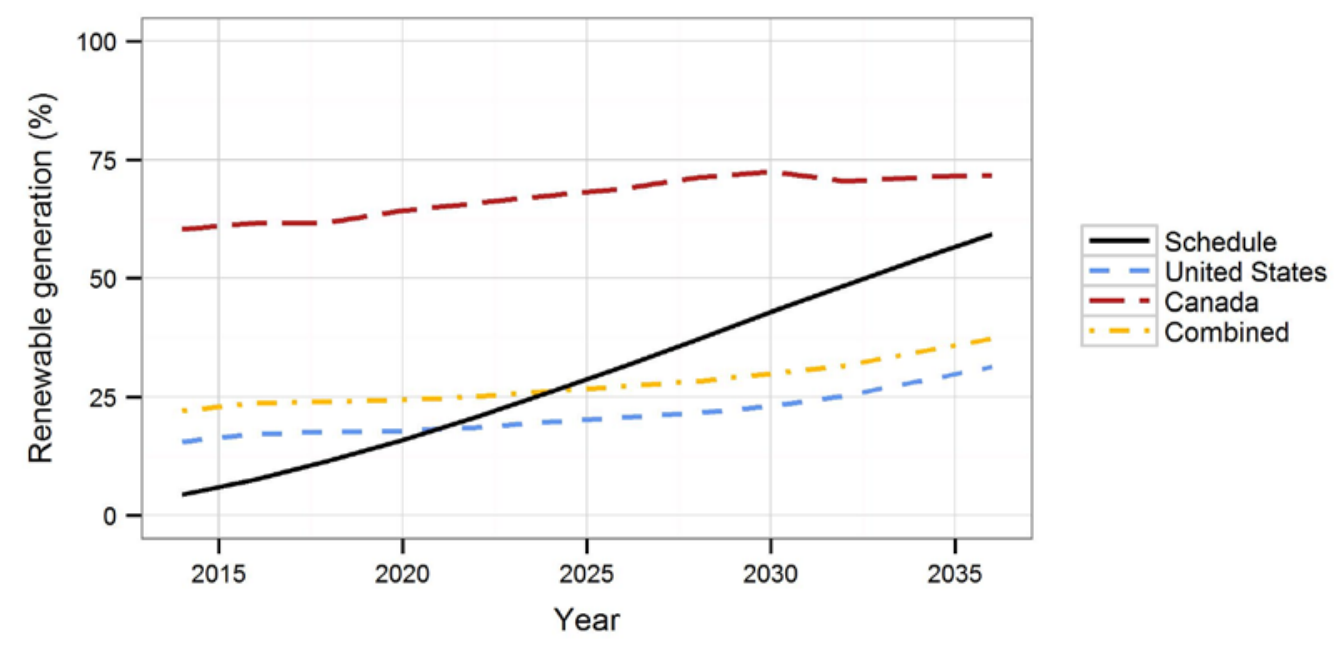

Figure 28. Fraction of generation from RE in "BaseCase" scenario, compared to RE requirement

Figure 29 and Figure 30 show the difference in capacity and generation by country for the RE sensitivities when compared to the "BaseCase" scenario. Under both scenarios, wind and PV installations in the United States experience significant growth, with a slight reduction in coal and gas CT capacity. The overall RE deployment behavior for Canada varies by RE sensitivity.

Under the "SeparateRE" scenario, the United States must rely on domestic RE generation to meet the requirement, and thus we observe an increase in RE generation in the United States, primarily from wind, PV and a small amount of CSP. This additional generation in the United States offsets the need for energy imports from Canada that would have otherwise occurred 
under the "BaseCase" scenario. The reduced need for Canadian imports results in reduced Canadian generation, leading primarily to reductions in Canadian wind deployment. ${ }^{21}$

In the "JointRE" scenario, the model chooses to utilize wind and PV capacity from both the United States and Canada to fulfill the requirement. The generation from RE resources replaces both coal and gas CC generation. While significant U.S. RE deployment is consistent across both scenarios, Canadian wind deployment increases significantly in "JointRE" to contribute to the combined RE requirement and serve U.S. energy demand.

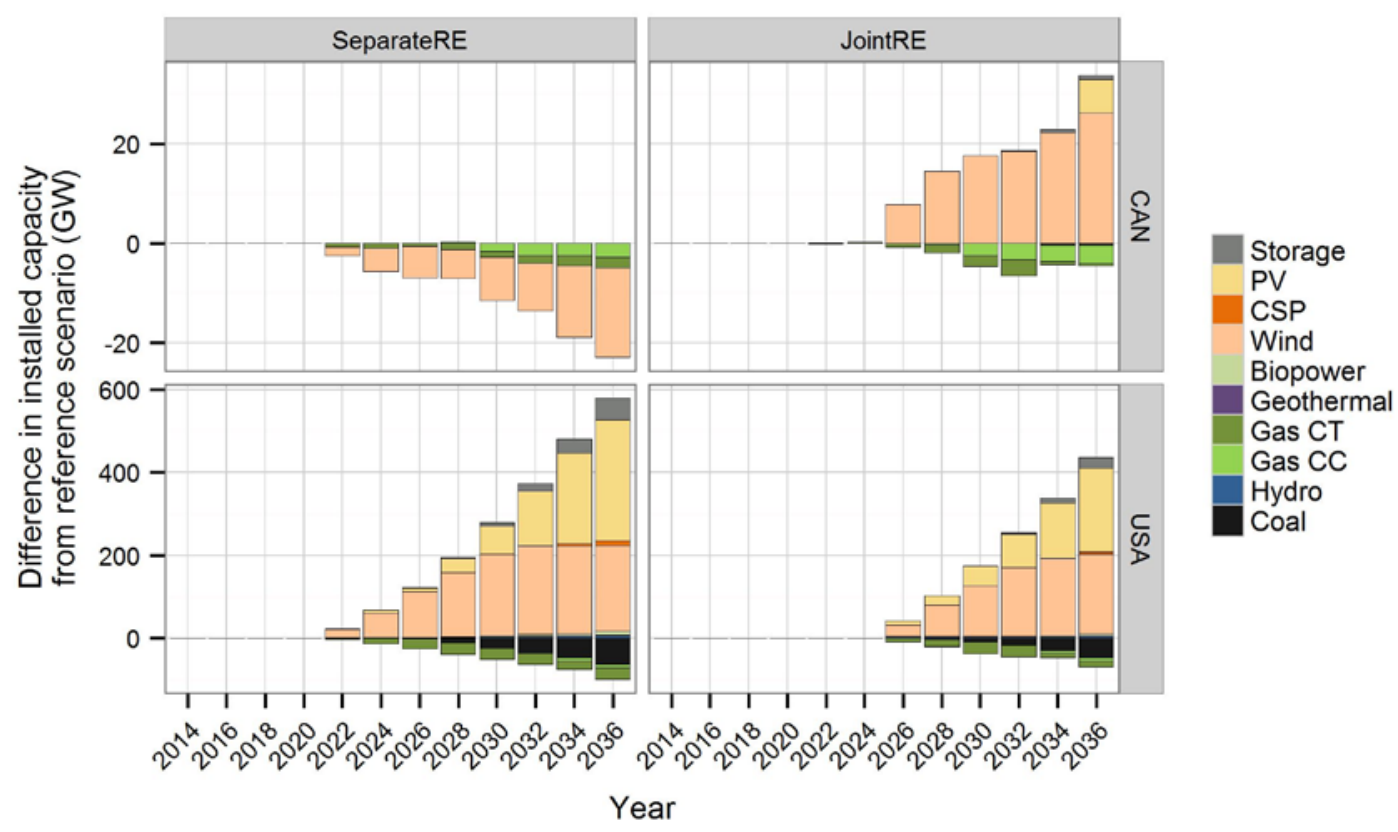

Figure 29. Change in capacity for high RE sensitivities, compared to "BaseCase" scenario

\footnotetext{
${ }^{21}$ As previously stated, Canadian RE capacity does not need to be deployed under the "SeparateRE" scenario to meet the imposed RE requirement. Canadian provinces simply deploy wind as a low-cost resource to meet energy demand.
} 


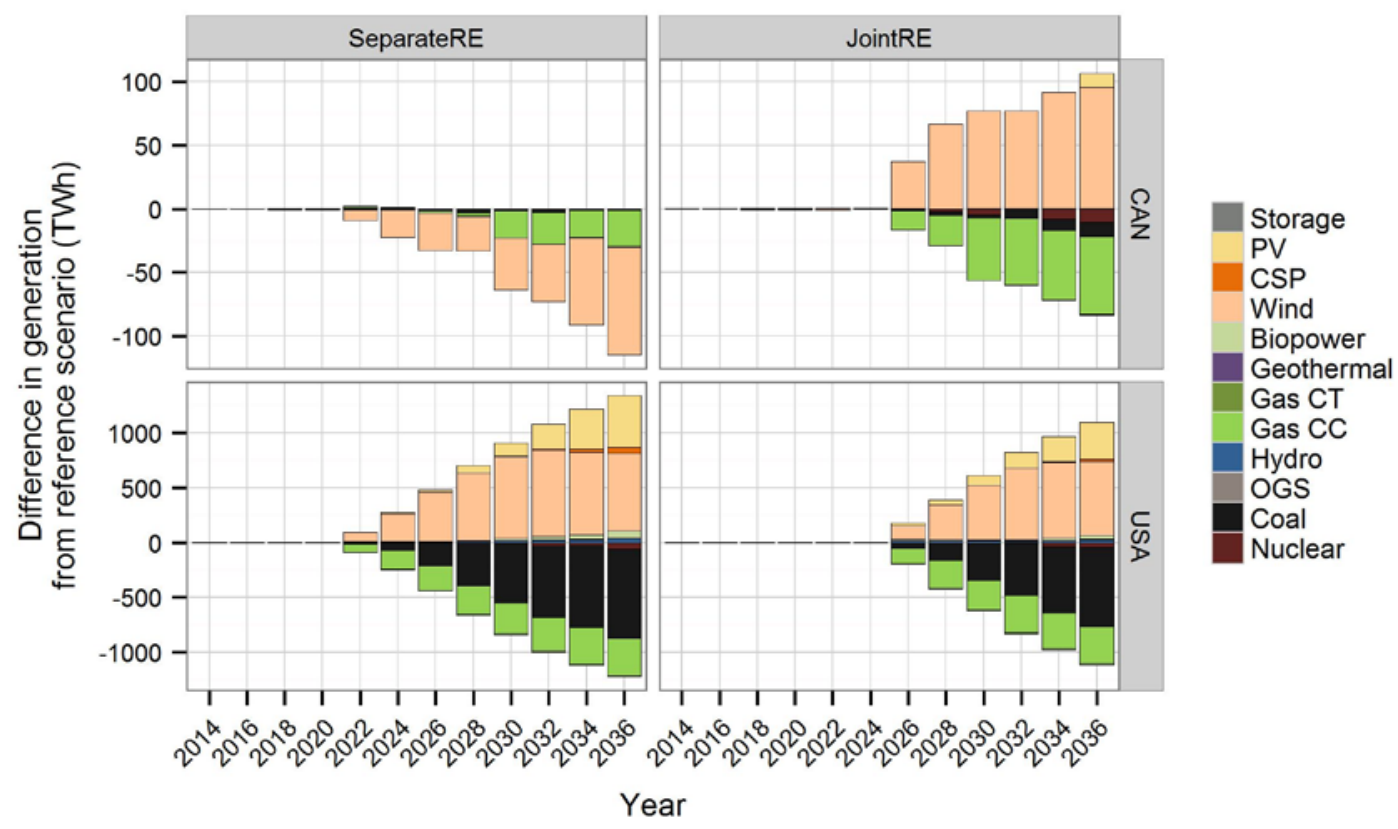

Figure 30. Change in generation for high RE sensitivities, compared to "BaseCase" scenario

Figure 31 shows the percentage of generation by country that comes from RE. It also includes the values for the two countries' combined RE generation percentage. Note that the combined RE penetration is higher in the "SeparateRE" scenario than in the "JointRE" scenario. This is because in the "SeparateRE" scenario, the U.S. must deploy a significant amount of RE regardless of Canada's existing high RE percentage. However, in the "JointRE" scenario, the countries can rely on Canada's existing RE generation fleet (mostly comprised of hydropower) to contribute toward the combined RE requirement.

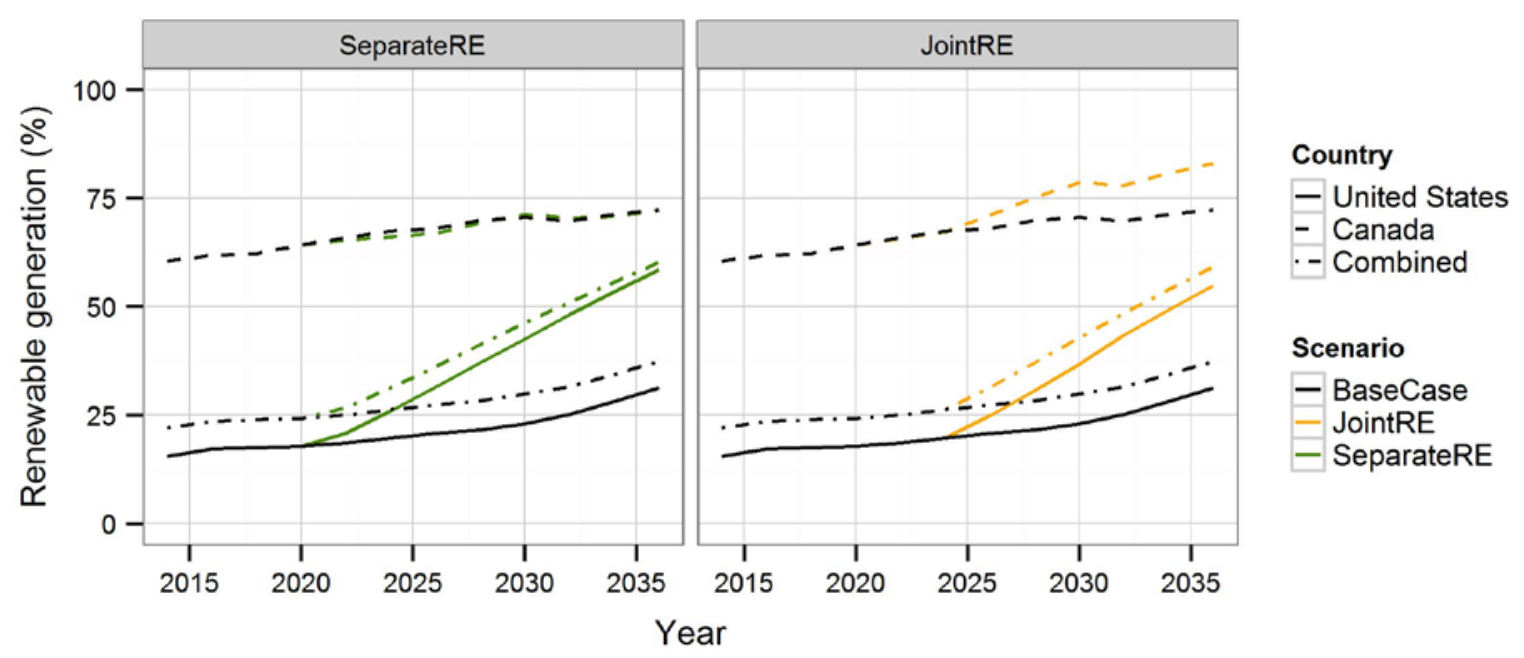

Figure 31. Fraction of generation from RE for the high RE sensitivities

Figure 32 shows net interchange between Canada and the United States for the high RE sensitivities. The "JointRE" scenario experiences an increase in Canadian wind deployment in 
the later years, increasing the imports from Canada. Conversely, the "SeparateRE" scenario installs more RE capacity in the United States and, thus, the direction of the net interchange switches around 2024 when the constraint becomes binding. From that point onward, the United States is a net exporter of energy to Canada. Total international transmission capacity does not change significantly.

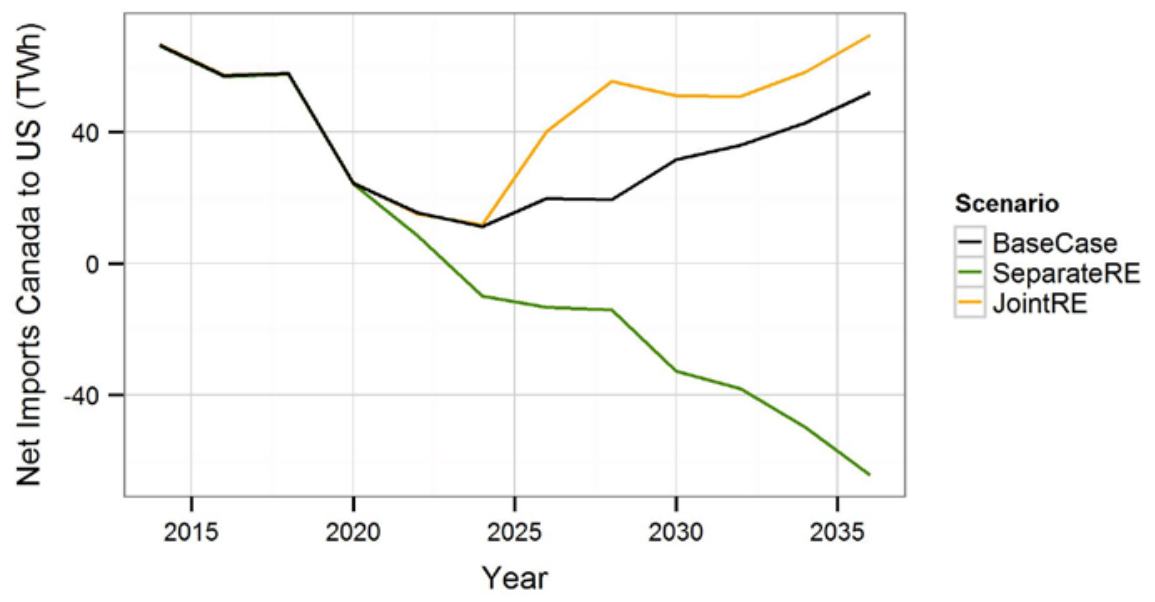

Figure 32. Net energy interchange between countries for the high RE sensitivities

\subsection{High Canadian Hydropower Sensitivity}

The final sensitivity considers an increase in Canadian hydropower capacity prescriptions. Given the lack of detailed cost data for potential hydropower sites in Canada (which is required by ReEDS to allow for robust least-cost decision-making), hydropower capacity is fixed and deployment is prescribed in all simulations. This sensitivity explores the effects of additional Canadian hydropower.

Figure 33 presents the differences in capacity between this sensitivity and the "BaseCase" scenario, while Figure 34 presents the differences in generation. The additional installed Canadian hydropower capacity mainly offsets wind deployment in Canada and some gas CT and PV deployment in the United States. There is a similar installation of gas CC capacity, but a reduction in their generation levels in both countries, to accommodate the additional low-cost generation from hydro. 


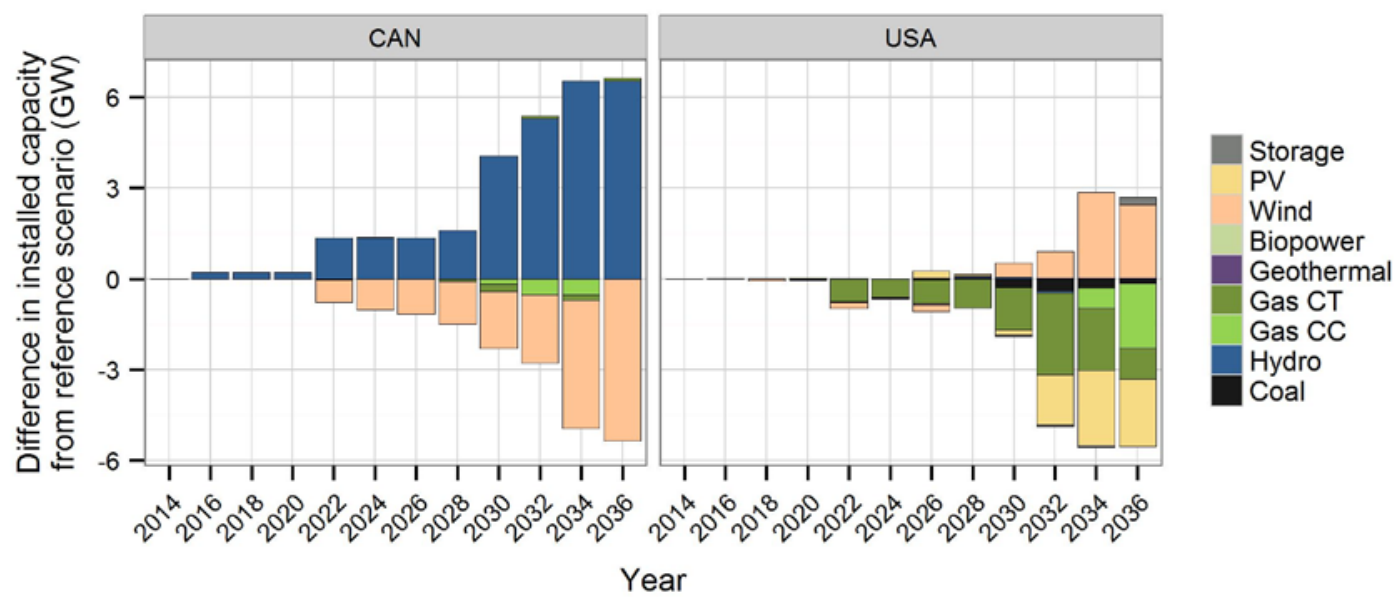

Figure 33. Change in capacity for "HiCanHydro" sensitivity, compared to "BaseCase" scenario

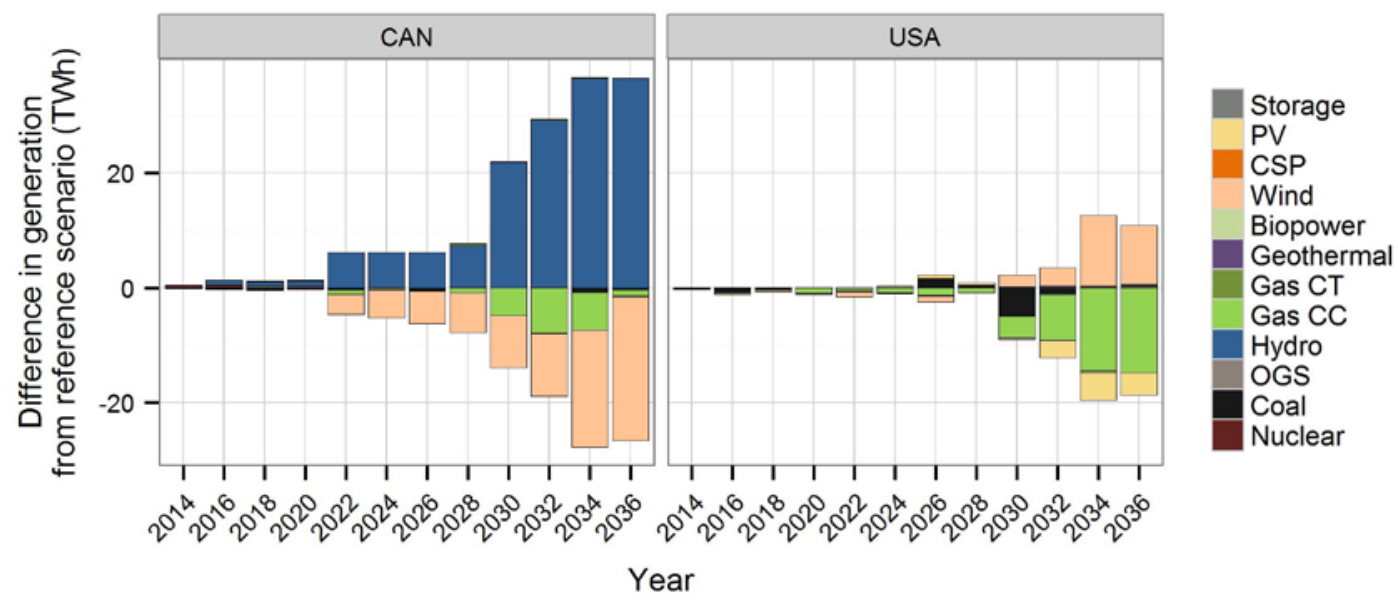

Figure 34. Change in generation for "HiCanHydro" sensitivity, compared to "BaseCase" scenario

The additional hydropower capacity in Canada decreases the need for new generation in the United States and ultimately increases exports from Canada to the United States (Figure 35). 


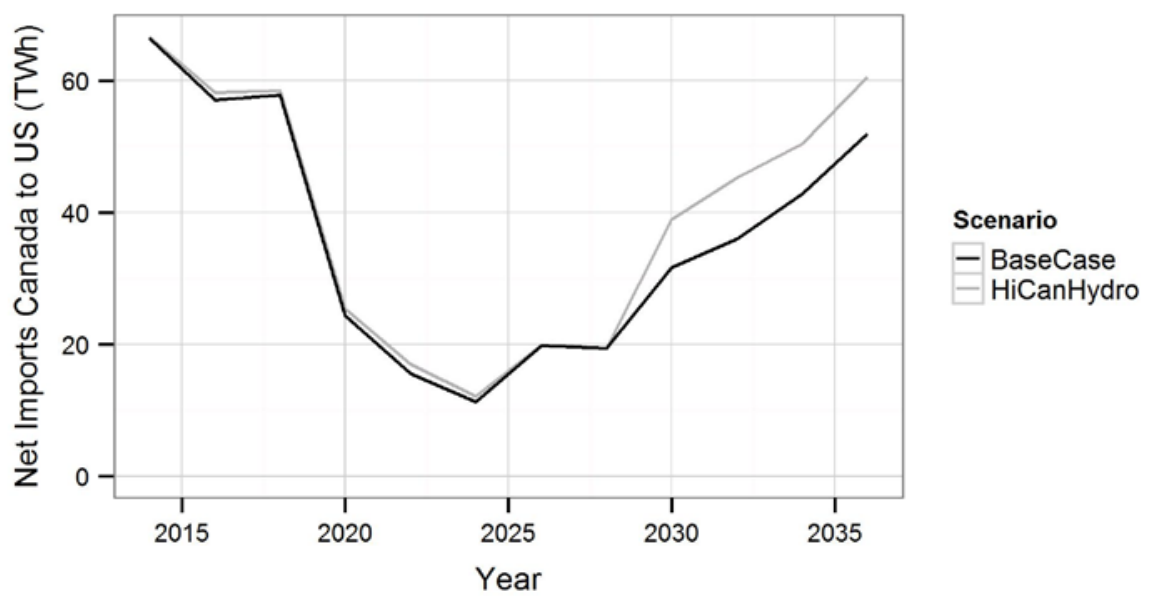

Figure 35. Net energy interchange between countries for the "HiCanHydro" sensitivity

\subsection{Summary of Results}

This section summarizes the results for all previously presented scenarios. First, we focus on the final generation mix by type by the end of the analysis period, presented in Figure 36. For Canada, the main difference across scenarios is the amount of wind and gas CC capacity. There is more wind installed in cases with favorable conditions, such as the "HiGas" and "JointRe" scenarios and it decreases significantly in the "LoGas" and "SeparateRE" scenarios. The "LoGas" scenario sees a significant increase in gas CC capacity and generation. Almost all the other sensitivities see smaller levels of gas CC generation, even when installed gas CC capacity remains the same (Figure 37).
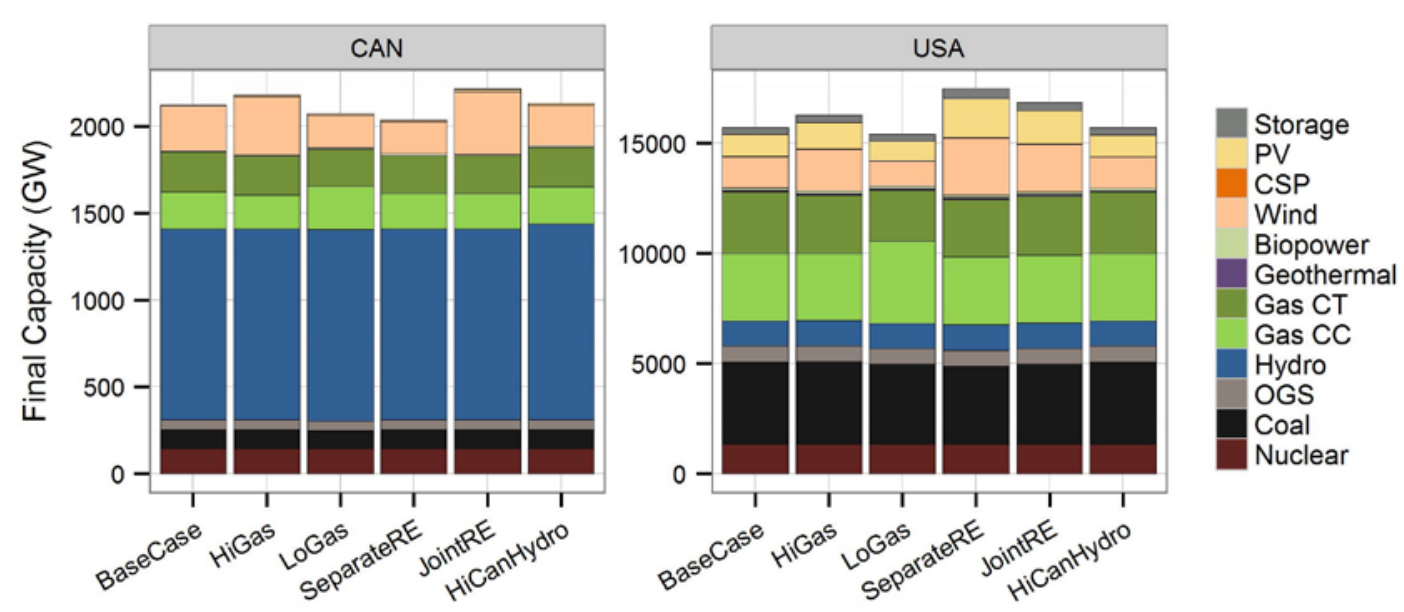

Figure 36. Capacity by type and country for all scenarios in 2036

The changes in the United States are similar. Capacity and generation from wind and solar increase in the "HiGas" and high RE scenarios. Those scenarios see a reduction in generation from gas CC (and coal in the case of the RE scenarios). In contrast, the "LoGas" scenario exhibits an increase in gas CC capacity and generation. 

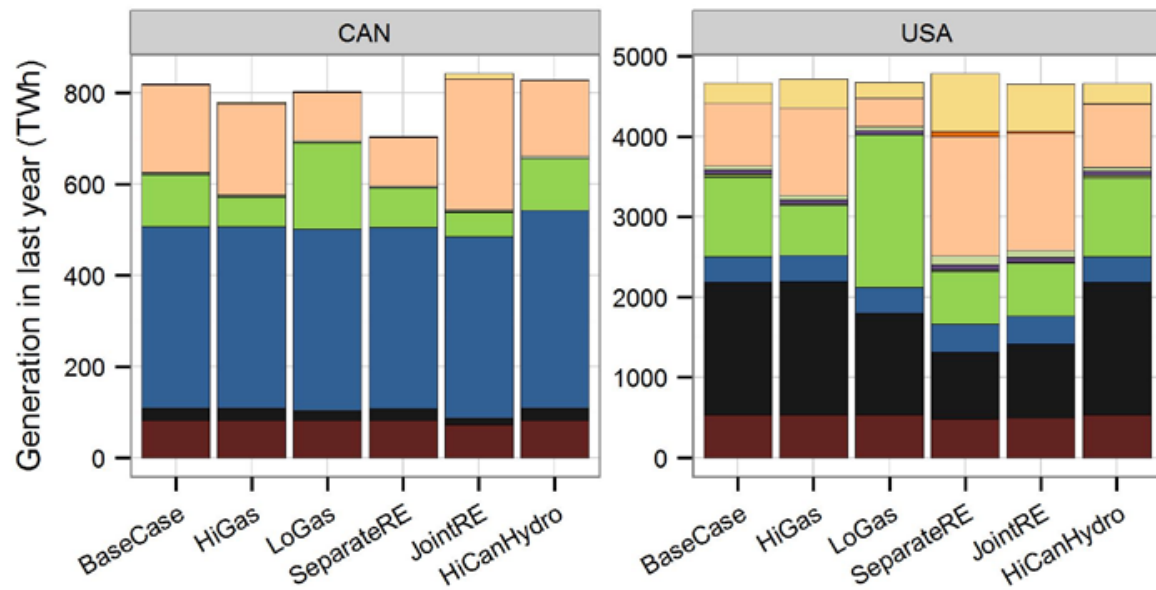

Storage

PV

CSP

Wind

Biopower

Geothermal

Gas CT

Gas CC

Hydro

OGS

Coal

Nuclear

Figure 37. Generation by type and country for all scenarios in 2036

The level of overall transmission construction is similar for most of the scenarios (Figure 38). The "HiCanHydro" scenario shows slightly higher builds, which are concentrated mainly in the west (Figure 39). For the most part, net imports from Canada decrease in early years, but generally stay positive for most scenarios. Net interchanges in the "SeparateRE" scenario actually continue the downward trend and, eventually, show a net import to Canada from the United States (Figure 40). This is driven by the need to install RE generation in the United States to meet its own RE requirement, while the Canadian requirement is never binding. This also causes the scenario to have the smallest development of new transmission across the border, particularly in the interface into NYISO (Figure 39). The exchange under the two natural gas sensitivities see a reduction in net energy imports (see section 4.2) and, consequently, there is a reduction in the international capacity deployed, particularly in the western interconnection.

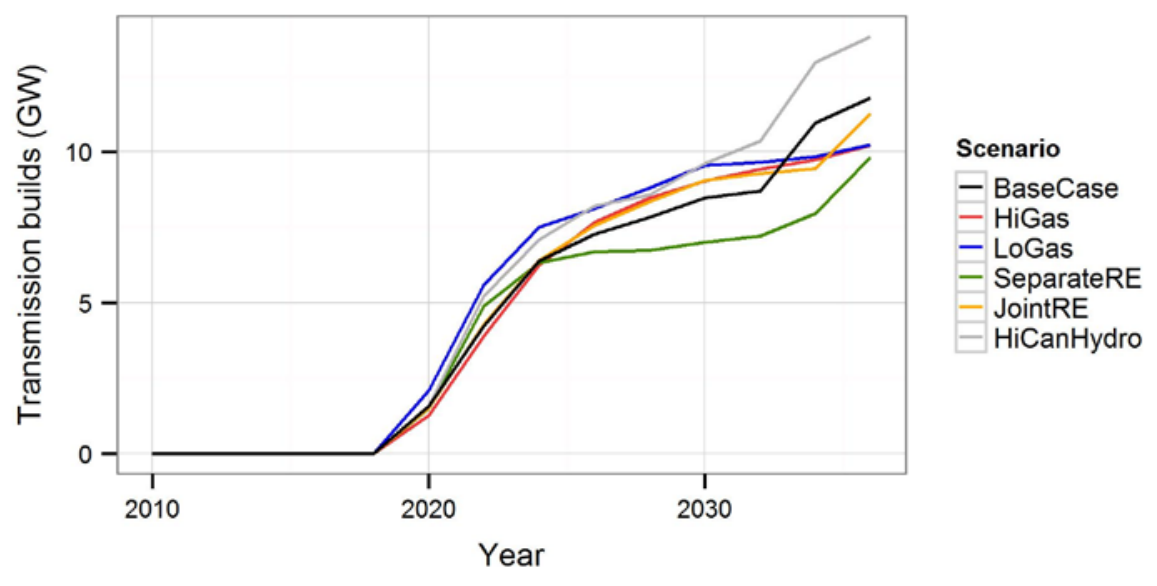

Figure 38. New international transmission capacity for all scenarios 


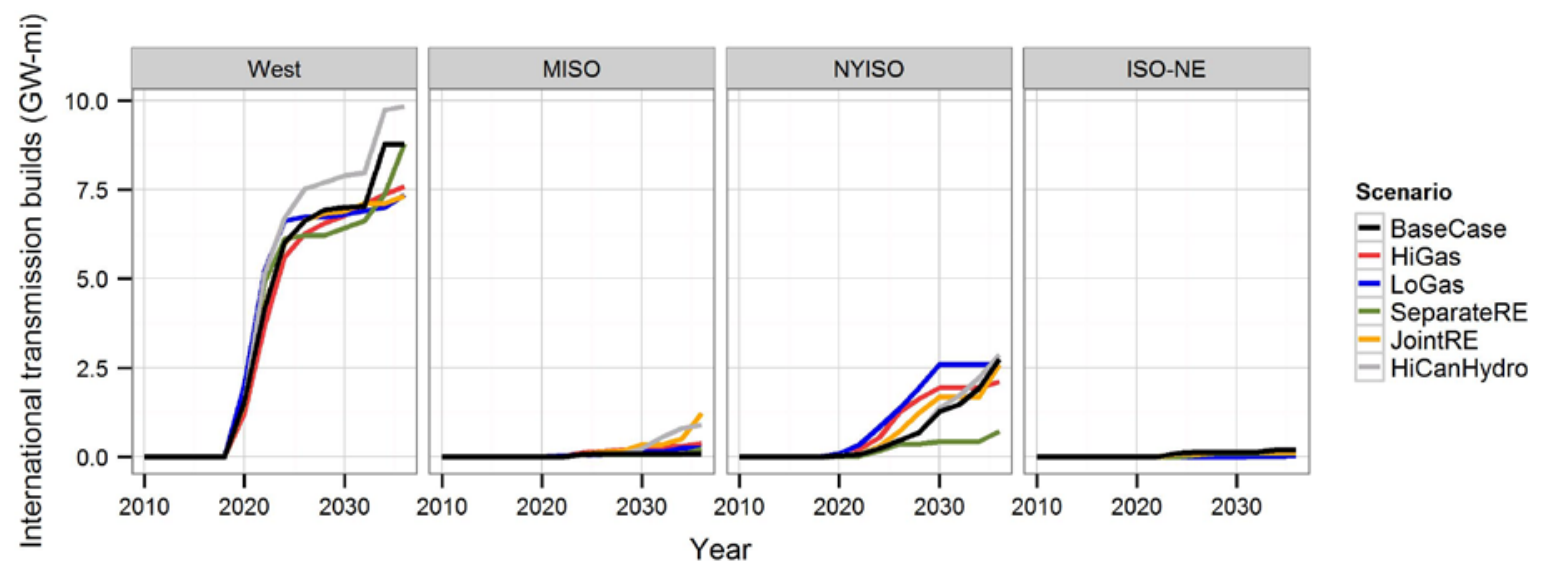

Figure 39. New international transmission capacity by zone for all scenarios

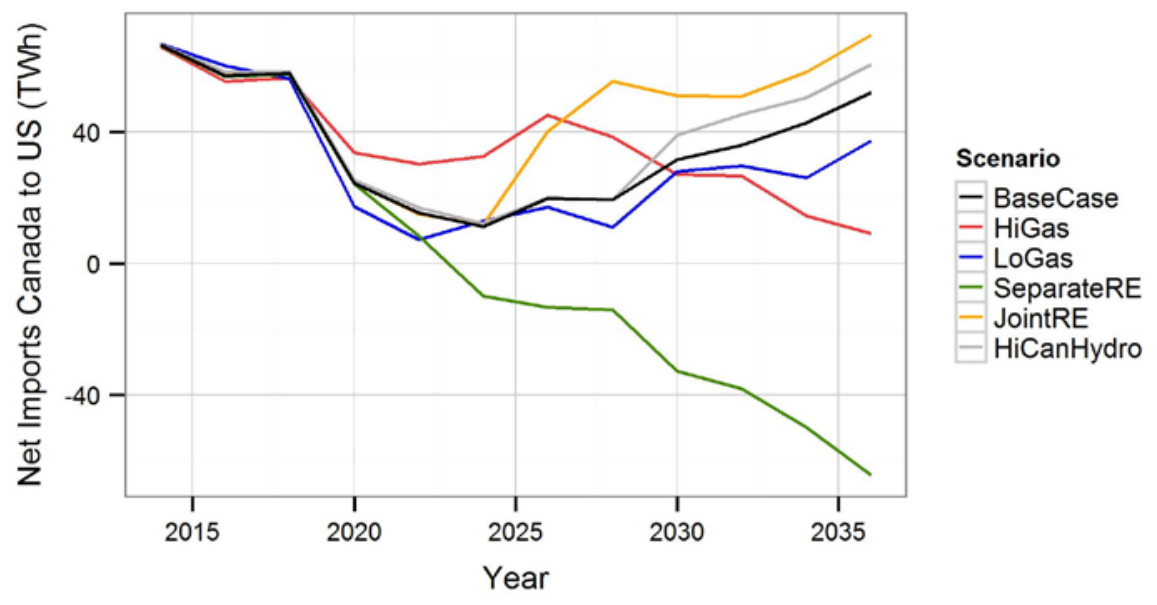

Figure 40. Net energy interchange between countries for all scenarios

Electricity prices in both countries remain relatively stable across scenarios (Figure 41, left). In 2036 , all electricity prices in the United States across all scenarios vary less than $\$ 7 / \mathrm{MWh}$, while the change is less than $\$ 4 / \mathrm{MWh}$ for Canada. Natural gas prices (Figure 41, right) are higher than the reference scenario assumptions for the "HiGas" scenario and lower for the "LoGas" scenario. For the high RE scenarios, all modeled behavior including natural gas prices remain identical to the reference scenario until the RE requirements become binding in 2022-2024. After that point, prices decrease as a result of lower demand from natural gas $\mathrm{CC}$ units. 

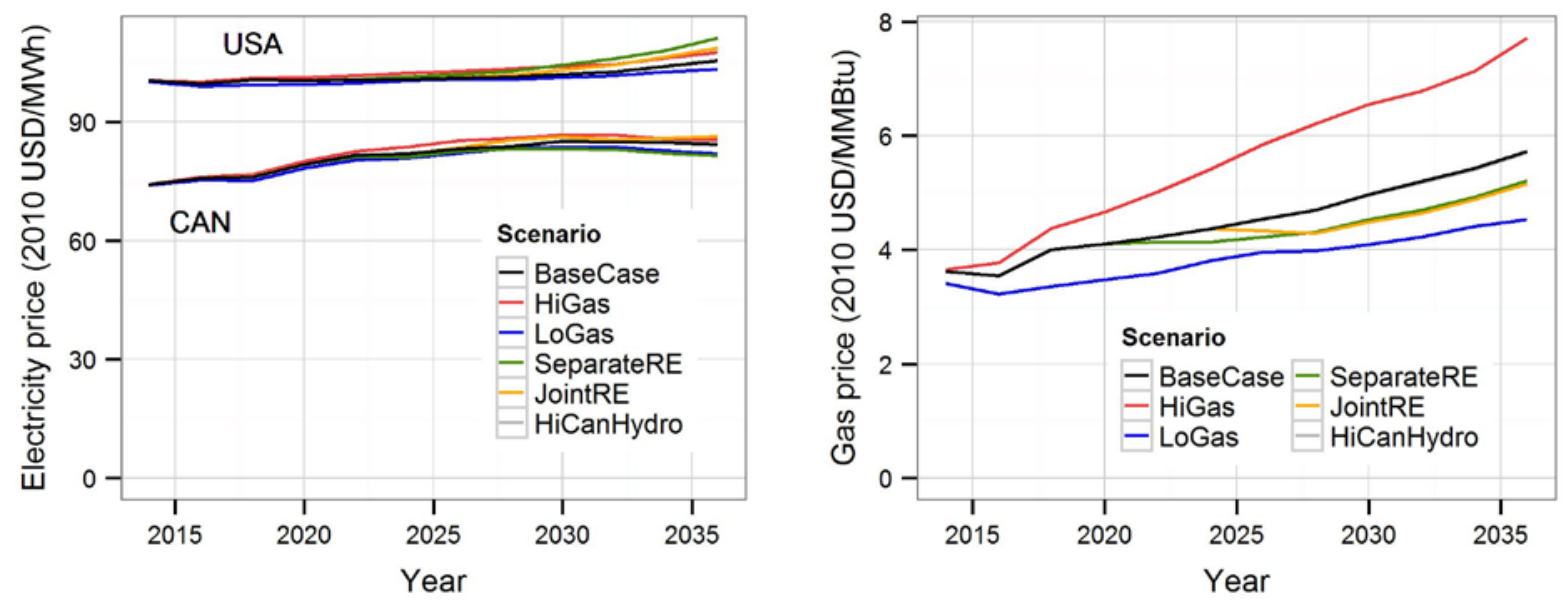

Figure 41. Electricity prices for Canada and the United States (left) and combined U.S./Canada natural gas prices (right) for all scenarios

The comparison of $\mathrm{CO}_{2}$ emissions by country across scenarios is also interesting (Figure 42). In Canada, $\mathrm{CO}_{2}$ emissions decrease for most scenarios, as more generation comes from wind and hydropower. This decrease is more pronounced in the "HiGas" and high RE scenarios. For the "LoGas" scenario, Canadian $\mathrm{CO}_{2}$ emissions are slightly higher than all other cases because there is a shift from wind generation to gas CC. For the United States, the most substantial $\mathrm{CO}_{2}$ reductions relative to the reference scenario appear in the high RE scenarios, followed by the "LoGas" scenario due to some coal-to-gas switching, increased wind deployment, and also because more energy is imported from Canada.

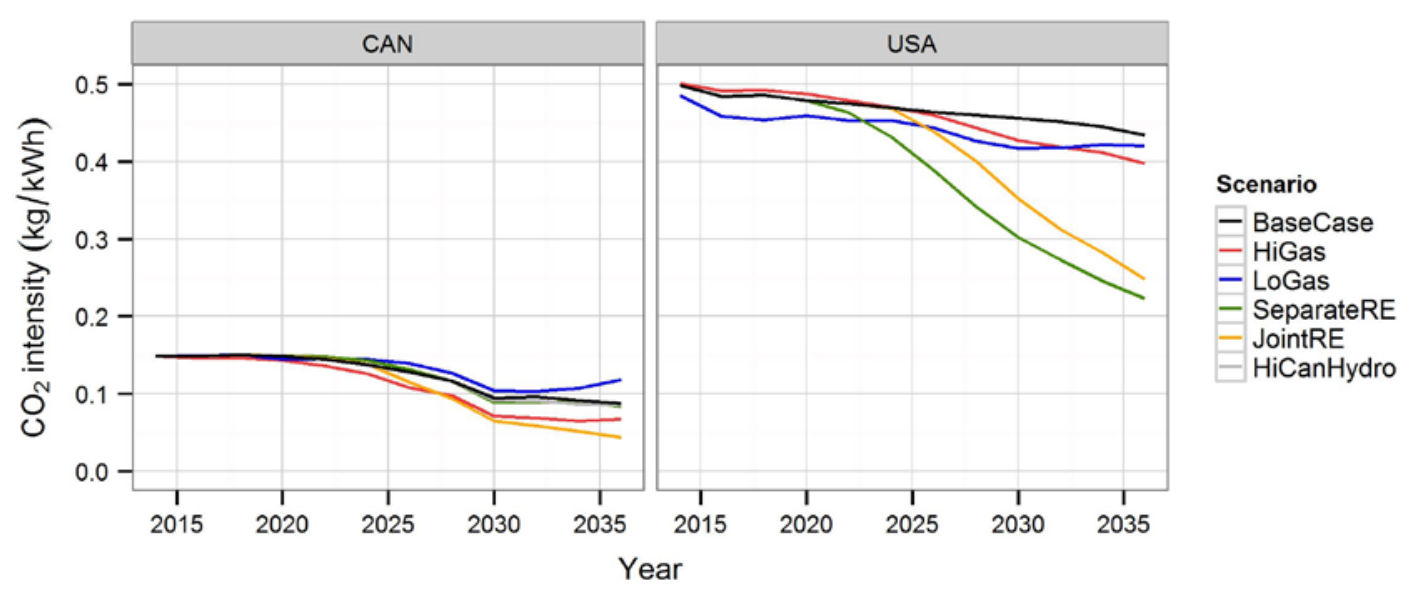

Figure 42. $\mathrm{CO}_{2}$ intensity by country for all scenarios 


\section{Conclusions and Next Steps}

This report documents a development effort to update an endogenous representation of the Canadian electricity sector in the NREL ReEDS Model, and presents results from an abbreviated scenario analysis to demonstrate new capabilities and explore a range of power sector futures.

The development effort was characterized by a series of data updates and augmentations to the representation of various power sector components. Amongst these updates are fuel price and load projections, the existing Canadian fleet characterization (including expected retirements and new builds), RE cost and performance assumptions and resource characterization, and existing regulations and policies.

A reference scenario is presented and analyzed in the analysis portion of this report. Five additional sensitivity scenarios are also presented.

The reference scenario results show a significant increase in wind generation in both the United States and Canada with a gradual retirement of coal and nuclear energy. The evolution of net energy and firm capacity exchange is very dynamic through the span of the analysis period and drives significant investment in transmission capacity across the border, almost doubling the existing capacity of transmission lines. The exchange of energy is driven by regional stories. ISO-NE and NYISO import energy throughout the analysis period. However, in the Western Interconnection we observe increasing imports to Canada from the United States, whereas the exchanges with MISO switch directions.

The five sensitivities present distinct evolutions of the U.S. and Canadian power systems. Higher natural gas prices result in higher levels of RE deployment in both countries and vice versa. Natural gas price projections have an effect on the interchange of energy between regions, driven by competition between gas $\mathrm{CC}$ and wind generation and the availability of those resources in different regions. However, transmission builds across the border do not vary substantially. The $\mathrm{RE}$ requirement scenarios exhibit distinct locational distributions of wind and PV deployment, depending on whether the requirement applies to each country separately or individually. Higher deployment of Canadian hydropower partially displaces some Canadian wind and U.S. gas CC deployment.

The work summarized in this report represents a unique approach to simulation of planning and operations of the electric system across the United States and Canada. This scenario analysis hints at the potential for Canada and the United States to benefit through collaborative actions, such as shared greenhouse-gas mitigation goals and transmission planning. Additional work to harmonize input assumptions on both sides of the border would increase the fidelity of the results. Of particular importance would be an in-depth assessment of the hydropower potential in Canada, captured through national supply curves following a similar methodology used for the U.S. resource. Similar updates to existing resource potential (e.g., wind) and development of resource potential data (e.g., geothermal) would further enhance the model. Future analysis will expand the scenario-based approach presented here and focus on the characterization of results as a function of input modification. 


\section{References}

AWEA (American Wind Energy Association). 2014. U.S. Wind Energy Annual Market Report, Year Ending 2013. Washington D.C.: American Wind Energy Association.

Bialek, J. (1996). "Tracing the Flow of Electricity in Generation, Transmission and Distribution.” IEEE Proceedings (143: 4); pp. 313-320.

Blair, Nate, Aron P. Dobos, Janine Freeman, Ty Neises, Michael Wagner, Tom Ferguson, Paul Gilman, and Steven Janzou. 2014. System Advisor Model, SAM 2014.1.14: General Description. NREL/TP-6A20-61019. Golden, CO: National Renewable Energy Laboratory.

British Columbia Ministry of Finance. 2015. "Carbon Tax: Overview of the revenue-neutral carbon tax." Accessed January 2015. http://www.fin.gov.bc.ca/tbs/tp/climate/carbon tax.htm.

CARB (California Air Resources Board). 2015. “Cap-and-Trade Program.” Accessed January 2015. http://www.arb.ca.gov/cc/capandtrade/capandtrade.htm.

CEA (Canadian Electricity Association). 2010. The Integrated Electricity System: Sustainable Electricity as the Foundation for Economic Recovery in North America. Ottawa, Ontario, Canada: Canadian Electricity Association. Accessed July 2014. http://www.electricity.ca/media/pdfs/economic/canada_us affairs/CEA_Enhancing_2010 final.p df

Clean Energy Act of 2010. Bill 17-2010. 2010 Legislative Session of British Columbia: 2nd Session, 39th Parliament. https://www.leg.bc.ca/39th2nd/1st_read/gov17-1.htm

Denholm, Paul, Easan, and Robert Margolis. 2009. Solar Deployment System (Solar DS) Model: Documentation and Base Case Results. NREL/TP-6A2-45832. Golden, CO: National Renewable Energy Laboratory.

DOE (U.S. Department of Energy). 2008. 20\% Wind Energy by 2030: Increasing Wind Energy's Contribution to U.S. Electricity Supply. Washington, D.C.: U.S. Department of Energy Office of Energy Efficiency and Renewable Energy. Accessed October 2014. www.20percentwind.org/20percent wind energy report revOct08.pdf.

- 2012. SunShot Vision Study. NREL/BK-5200-47927; DOE/GO-102012-3037.

Washington, D.C.: U.S. Department of Energy Office of Energy Efficiency and Renewable Energy. Accessed October 24, 2014. http://www.nrel.gov/docs/fy12osti/47927.pdf.

- 2015. Wind Vision: A New Era for Wind Power in the United States. Washington, D.C. http://www.energy.gov/windvision.

EIA (U.S. Energy Information Administration). 2014. Annual Energy Outlook 2014. DOE/EIA0383(2014). Washington, D.C.: Energy Information Administration.

Environment Canada. 2008. "Canadian Wind Energy Atlas." Fredericton, New Brunswick, Canada: Environment Canada. Accessed November 2014. http://www.windatlas.ca 
- (2014). "Canadian Weather year for Energy Calculation (CWEC).” Fredericton, New Brunswick, Canada: Environment Canada. Accessed November 2014. http://climate.weather.gc.ca/prods_servs/engineering_e.html.

EPA (U.S. Environmental Protection Agency). 2014a. “40 CFR Parts 60, 70, 71, et al.: Standards of Performance for Greenhouse Gas Emissions From New: Stationary Sources: Electric Utility Generating Units; Proposed Rule." 79 Fed. Reg. 117 (June 18, 2014). Accessed November 7 , 2014. http://www.gpo.gov/fdsys/pkg/FR-2014-06-18/pdf/2014-13726.pdf.

- 2014b. "40 CFR Part 60: Carbon Pollution Emission Guidelines for Existing Stationary Sources: Electric Utility Generating Units; Proposed Rule.” 79 Fed. Reg. 117. (June 18, 2014). Accessed November 7, 2014. http://www.gpo.gov/fdsys/pkg/FR-2014-06-18/pdf/201413726.pdf.

Logan, Jeffrey, Anthony Lopez, Trieu Mai, Carolyn Davidson, Morgan Bazilian, and Douglas Arent. 2013. "Natural Gas Scenarios in the U.S. Power Sector." Energy Economics 40:183-95. Accessed October 2014. http://dx.doi.org/10.1016/j.eneco.2013.06.008.

Mai, Trieu, David Mulcahy, M. Maureen Hand, and Samuel F. Baldwin. 2014. "Envisioning a Renewable Electricity Future for the United States." Energy 65:1;374-86. Accessed December 2014. http://dx.doi.org/10.1016/j.energy.2013.11.029.

Martinez, Andrew, Kelly Eurek, Trieu Mai, and Andrew Perry. 2013. Integrated Canada-U.S. Power Sector Modeling with the Regional Energy Deployment System (ReEDS). NREL/TP6A20-56724. Golden, CO: National Renewable Energy Laboratory.

NEB (National Energy Board). 2013. Canada's Energy Future 2013 - Energy Supply and Demand Projections to 2035. Calgary, Alberta, Canada: National Energy Board. Accessed October 20, 2014. https://www.neb-one.gc.ca/nrg/ntgrtd/ftr/2013/2013nrgftr-eng.pdf.

NREL (National Renewable Energy Laboratory). 2012. Renewable Electricity Futures Study. Edited by M.M. Hand, S. Baldwin, E. DeMeo, J.M. Reilly, T. Mai, D. Arent, G. Porro, M. Meshek, D. Sandor. 4 vols. NREL/TP-6A20-52409. Golden, CO: National Renewable Energy Laboratory.

_. 2014. Annual Technology Baseline and Standard Scenarios. Accessed November 2014. http://www.nrel.gov/analysis/data tech baseline.html

OME (Ontario Ministry of Energy). 2013. Achieving Balance: Ontario's Long Term Energy Plan. Ontario, Canada: Ontario Ministry of Energy. Accessed October 2014. http://www.energy.gov.on.ca/en/files/2014/10/LTEP 2013 English_WEB.pdf.

RGGI (Regional Greenhouse Gas Initiative). (2015). New York, New York, USA: Regional Greenhouse Gas Initiative. Accessed January 2015. http://www.rggi.org/. 
Short, Walter, Patrick Sullivan, Trieu Mai, Matthew Mowers, Caroline Uriarte, Nate Blair, Donna Heimiller, and Andrew Martinez. 2011. Regional Energy Deployment System (ReEDS). NREL/TP-6A20-46534. Golden, CO: National Renewable Energy Laboratory. Accessed October 2014: http://www.nrel.gov/analysis/reeds/pdfs/reeds_documentation.pdf. 